\title{
3D cloud reconstructions: evaluation of scanning radar scan strategy with a view to surface shortwave radiation closure
}

Article

Published Version

Fielding, M. D., Chiu, J. C., Hogan, R. J. and Feingold, G. (2013) 3D cloud reconstructions: evaluation of scanning radar scan strategy with a view to surface shortwave radiation closure. Journal of Geophysical Research: Atmospheres, 118 (16). pp. 9153-9167. ISSN 2169-8996 doi: https://doi.org/10.1002/jgrd.50614 Available at https://centaur.reading.ac.uk/33726/

It is advisable to refer to the publisher's version if you intend to cite from the work. See Guidance on citing.

To link to this article DOI: http://dx.doi.org/10.1002/jgrd.50614

Publisher: American Geophysical Union

All outputs in CentAUR are protected by Intellectual Property Rights law, including copyright law. Copyright and IPR is retained by the creators or other copyright holders. Terms and conditions for use of this material are defined in the End User Agreement. 


\section{CentAUR}

Central Archive at the University of Reading

Reading's research outputs online 


\title{
3D cloud reconstructions: Evaluation of scanning radar scan strategy with a view to surface shortwave radiation closure
}

\author{
Mark D. Fielding, ${ }^{1}$ J. Christine Chiu, ${ }^{1}$ Robin J. Hogan, ${ }^{1}$ and Graham Feingold ${ }^{2}$ \\ Received 29 January 2013; revised 23 June 2013; accepted 28 June 2013.
}

[1] The ability of six scanning cloud radar scan strategies to reconstruct cumulus cloud fields for radiation study is assessed. Utilizing snapshots of clean and polluted cloud fields from large eddy simulations, an analysis is undertaken of error in both the liquid water path and monochromatic downwelling surface irradiance at $870 \mathrm{~nm}$ of the reconstructed cloud fields. Error introduced by radar sensitivity, choice of radar scan strategy, retrieval of liquid water content (LWC), and reconstruction scheme is explored. Given an infinitely sensitive radar and perfect LWC retrieval, domain average surface irradiance biases are typically less than $3 \mathrm{~W} \mathrm{~m}^{-2} \mu \mathrm{m}^{-1}$, corresponding to $5-10 \%$ of the cloud radiative effect (CRE). However, when using a realistic radar sensitivity of $-37.5 \mathrm{dBZ}$ at $1 \mathrm{~km}$, optically thin areas and edges of clouds are difficult to detect due to their low radar reflectivity; in clean conditions, overestimates are of order $10 \mathrm{~W} \mathrm{~m}^{-2} \mu \mathrm{m}^{-1}$ ( $20 \%$ of the CRE), but in polluted conditions, where the droplets are smaller, this increases to $10-26 \mathrm{~W} \mathrm{~m}^{-2} \mu \mathrm{m}^{-1}(\sim 40-100 \%$ of the CRE). Drizzle drops are also problematic; if treated as cloud droplets, reconstructions are poor, leading to large underestimates of $20-46 \mathrm{~W} \mathrm{~m}^{-2} \mu \mathrm{m}^{-1}$ in domain average surface irradiance ( $\sim 40-80 \%$ of the CRE). Nevertheless, a synergistic retrieval approach combining the detailed cloud structure obtained from scanning radar with the droplet-size information and location of cloud base gained from other instruments would potentially make accurate solar radiative transfer calculations in broken cloud possible for the first time.

Citation: Fielding, M. D., J. C. Chiu, R. J. Hogan, and G. Feingold (2013), 3D cloud reconstructions: Evaluation of scanning radar scan strategy with a view to surface shortwave radiation closure, J. Geophys. Res. Atmos., 118, doi:10.1002/ jgrd.50614.

\section{Introduction}

[2] Clouds play a key role in determining Earth's radiation budget, but represent one of the greatest challenges in simulating climate change [Randall et al., 2007]. Due to their complex three-dimensional (3D) structure, fundamentally linked to cloud-radiation feedbacks [Stephens, 2005], clouds remain the subject of much research for radiation closure studies and parameterization in models [e.g., Shonk et al., 2012]. We define radiation closure as "having sufficient knowledge of the optical properties of the surface and of gases, clouds and aerosol in the atmosphere, so that spectral radiation fluxes can be predicted using a radiation model to climate requirements (typically $1-2 \mathrm{~W} \mathrm{~m}^{-2}$ )." Obtaining shortwave (SW) radiation closure, which has not been conclusively achieved, will allow us to have confidence in both atmospheric observations and radiation models. In particular, robust observations of cloud are essential to further many areas of research, yet are notoriously difficult to make.

\footnotetext{
${ }^{1}$ Department of Meteorology, University of Reading, Reading, UK.

${ }^{2}$ NOAA Earth System Research Laboratory, Boulder, Colorado, USA.

Corresponding author: M. D. Fielding, Department of Meteorology, University of Reading, Earley Gate, PO Box 243, Reading RG6 6BB, UK. (m.d.fielding@pgr.reading.ac.uk)

(C)2013. American Geophysical Union. All Rights Reserved. 2169-897X/13/10.1002/jgrd.50614
}

[3] Cumulus clouds are a common sight almost anywhere on Earth [Rossow and Schiffer, 1999], yet until recently, not only has obtaining a high-resolution 3D field of liquid water content (LWC) matching the truth been considered an out-of-reach task [Benner and Evans, 2001], but also generating a statistically correct representation is problematic [Schmidt et al., 2007], not least because of difficulties in validation. To account for cloud heterogeneity, Pincus et al. [2005] showed how a vertically pointing radar could be used to obtain 3D cloud fields. They turned the 2D view obtained by the advection of clouds over the radar to 3D by keeping one horizontal dimension constant. Using shallow cumulus clouds from a large eddy simulation (LES), they found errors up to $25 \mathrm{~W} \mathrm{~m}^{-2}$ in broadband SW surface irradiances, which is significant when the total cloud radiative effect (CRE) on the energy budget was $50-70 \mathrm{~W} \mathrm{~m}^{-2}$. This prompted the need for a different way to acquire $3 \mathrm{D}$ cloud fields.

[4] By approximating certain statistical relationships derived from observations, stochastic models have also been used to generate 3D cloud fields and to explore CREs; examples include Di Giuseppe and Tompkins [2003] for stratocumulus, Evans and Wiscombe [2005] and Prigarin and Marshak [2009] for cumulus, and Hogan and Kew [2005] for cirrus. Using stochastic cloud generators, Hinkelman et al. [2007] found that cloud anisotropy in cumulus gave rise to instantaneous downwelling broadband SW irradiance 


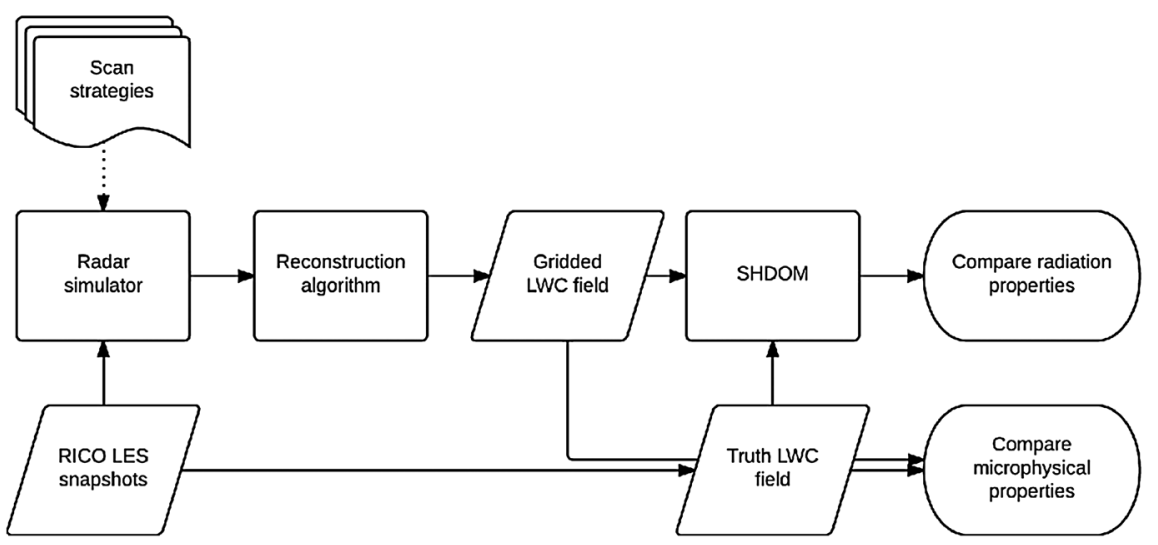

Figure 1. Flowchart illustrating the method to test different scan strategies. A radar simulator uses one of six scan strategies (see Table 1 and Figure 2) to generate observations from a LES model-generated ("truth") cloud field. The simulated observations are then gridded using the reconstruction algorithm. A radiative transfer model is used to calculate the difference in downwelling surface irradiance between reconstructed and truth cloud fields. Abbreviation key: RICO LES (Large Eddy Simulation forced with data from the Rain In Cumulus over Ocean campaign); LWC (liquid water content), and SHDOM (a 3D radiative transfer model using Spherical Harmonics Discrete Ordinates Method).

errors of up to $40 \mathrm{~W} \mathrm{~m}^{-2}$ (up to $10 \%$ relative to the total irradiance), with large variations for different solar zenith angle (SZA). Venema et al. [2006] showed that such stochastic models are capable of reproducing almost identical domain-averaged broadband radiative irradiances in simulated stratocumulus fields. Similarly, Schmidt et al. [2007] used cloud generators to upscale 1D flight path measurements of cloud LWC and effective radius, and found that the domain-averaged SW irradiance error below cloud was $12-50 \mathrm{~W} \mathrm{~m}^{-2} \mu \mathrm{m}^{-1}(\sim 1.5 \%-7 \%)$ for a broken cloud case. Overall, cloud generators have been shown to give good representations of modeled clouds, but evaluating their performance is challenging because of the lack of true $3 \mathrm{D}$ cloud observations.

[5] New scanning cloud radar provides the potential for direct observations of cloud structure in 3D, bypassing the need for cloud generators. The Atmospheric Radiation Measurement (ARM; see Ackerman and Stokes [2003]) Climate Research Facility has deployed scanning cloud radars that employ a wide range of scanning strategies for the study of cloud lifetime cycle and reconstruction of cloud fields with an eye towards radiation closure. The objective of this paper is to assess the potential ability of the ARM standard scan strategies, as well as other novel strategies, to reconstruct 3D clouds for studying cloud-radiation interactions. In this study, we use a radar simulator and cumulus cloud fields generated by an LES to address both microphysical and radiative integrity of the reconstructions. As this is one of the first studies to quantitatively evaluate the ability of scanning radar to reconstruct cloud fields, we take a broad view of the problem and do not, as such, provide a new cloud retrieval algorithm for radiation closure. The key questions we aim to answer are:

[6] 1. Which scan strategies are most appropriate for maximising cloud information in support of SW surface radiation closure?

[7] 2. What is the contribution of small clouds to domainaveraged surface downwelling irradiances?
[8] 3. What sources of error in cloud reconstruction are likely to have the biggest impact on calculated surface irradiance measurements?

[9] The paper is organized as follows: In section 2, the LES-generated "truth" cloud field is described, followed by the methodology for cloud reconstruction from simulated radar scans. In section 3 , the scan strategies are compared through a series of experiments, with subsections detailing different sources of error in the reconstruction. Finally, section 4 draws conclusions and summarizes the work.

\section{Experiment Setup}

[10] This section describes the experiment setup, as illustrated in Figure 1. A radar simulator uses one of six scan strategies (see Table 1 and Figure 2) to generate observations from a truth cloud field. The simulated observations are then gridded using the reconstruction method. A radiative transfer model is used to calculate the difference in downwelling surface irradiance between reconstructed and truth cloud fields.

\subsection{Cloud Fields Scanned by Radars}

[11] To investigate which radar scan strategy best captures 3D cloud structure, we tested shallow cumulus clouds that pose a great challenge for both radar scanning and cloud field reconstruction. These cumulus clouds were generated by a LES model with forcing data collected from the Rain In Cumulus over Ocean (RICO) campaign [Jiang et al., 2009]. The model has been evaluated against other LES models and RICO observations [vanZanten et al., 2011]. The domain size is $6.4 \times 6.4 \times 4 \mathrm{~km}$, with grid spacing of $25 \times 25 \times 10 \mathrm{~m}$ and periodic boundary conditions in the horizontal. Cloud base heights are about $800 \mathrm{~m}$ with cloud depth varying from $50 \mathrm{~m}$ to $1000 \mathrm{~m}$. We capitalize on the size-resolved (bin) representation of cloud microphysical processes so that no assumptions need to be made about the shape of the drop size distribution. Using the drop size distributions characterized by 33 bins with diameter range $3-5800 \mu \mathrm{m}$ and assuming Rayleigh scattering for cloud 
Table 1. Scan Mode Specifications ${ }^{\mathrm{a}}$

\begin{tabular}{|c|c|c|c|}
\hline Scan Mode & Resolution $^{\mathrm{b}}\left({ }^{\circ}\right)$ & \# of Scan Slices per $5 \mathrm{~min}$ & Notes \\
\hline HSRHI & $\theta=[1: 1: 179], \varphi=[0: 30: 180]^{\mathrm{c}}$ & 30 & Horizon to horizon scan \\
\hline $\mathrm{SOHO}$ & $\theta=[1: 1: 179] ; \varphi=[0: 6: 180]$ & 30 & $\begin{array}{l}\text { Sydney Opera HOuse generating slanted segments; same as HSRHI } \\
\text { with zenith rotated to horizon }\end{array}$ \\
\hline PPI & $\begin{aligned} \theta & =[1: 3: 30 ; 35: 5: 90] \\
\varphi & =[0: 1: 359 ; 0: 5: 355]\end{aligned}$ & 20 & $\begin{array}{c}\text { Plan position indicator scan, decreased resolution at higher } \\
\text { elevation angles }\end{array}$ \\
\hline Sector RHI & $\theta=[1: 1: 90] ; \varphi=[0: 1.5: 90]$ & 60 & $\begin{array}{l}\text { Horizon to zenith scan, with radar at corner of domain scanning with a } \\
90^{\circ} \text { azimuth range }\end{array}$ \\
\hline Sector PPI & $\begin{array}{c}\theta=[1: 3: 30 ; 35: 5: 90] \\
\varphi=[0: 1: 90]\end{array}$ & 50 & $\begin{array}{l}\text { Plan position indicator scan, with radar at corner of domain scanning with a } \\
\qquad 90^{\circ} \text { azimuth range }\end{array}$ \\
\hline CWRHI & $\theta=[10: 1: 170] ; \varphi=$ fixed & $30+^{\mathrm{d}}$ & Horizon to horizon scan, with azimuth fixed perpendicular to the wind \\
\hline
\end{tabular}

${ }^{a}$ Elevation angles $\theta$ and azimuth angles $\varphi$ for each scan mode are defined in the resolution column. Each scan mode was designed to match the specification of ARM's scanning radar. Visualizations for each scan mode can be found in Figure 2.

${ }^{b}$ Described by $\left[\delta_{1}: \delta_{2}: \delta_{3}\right]$, where $\delta_{1}$ is the starting angle, $\delta_{2}$ is the angle interval, and $\delta_{3}$ is the ending angle.

${ }^{\mathrm{c}}$ Azimuth angles are offset by $6^{\circ}$ every 6 slices to minimize gaps in the domain.

${ }^{\mathrm{d}}$ Wind dependent, 30 slices per $5 \mathrm{~min}$ scan time period.

droplets at the radar wavelength, LWC, effective radius $\left(r_{\mathrm{e}, \text { true }}\right)$, and radar reflectivity $(\mathrm{dBZ})$ for each grid point are given as:

$$
\begin{gathered}
L W C=\frac{\pi}{6} \rho_{w} \sum_{i=1}^{33} N\left(D_{i}\right) D_{i}^{3} \\
r_{e, t r u e}=\sum_{i=1}^{33} N\left(D_{i}\right) D_{i}^{3} / 2 \sum_{i=1}^{33} N\left(D_{i}\right) D_{i}^{2}
\end{gathered}
$$

and

$$
d B Z=10 \log _{10}\left(\sum_{i=1}^{33} N\left(D_{i}\right) D_{i}^{6}\right)
$$

where $\rho_{\mathrm{w}}$ is the density of liquid water, and $D_{\mathrm{i}}$ and $N\left(D_{\mathrm{i}}\right)$ are the average drop diameter and the number of droplets in the $i$ th bin, respectively. In equation (3), $D_{\mathrm{i}}$ and $N\left(D_{\mathrm{i}}\right)$ are in units of $\mathrm{mm}$ and $\mathrm{m}^{-3}$.

[12] To test a diverse range of cloud and droplet sizes, we include one "clean" case and one "polluted" case that were, respectively, initialized with $100 \mathrm{~cm}^{-3}$ and $1000 \mathrm{~cm}^{-3}$ hygroscopic aerosol particles [Koren et al., 2008; Jiang et al., 2009]. Sample snapshots from both cases are shown in Figures $4 \mathrm{a}$ and $5 \mathrm{a}$, corresponding to liquid water paths (LWPs) up to $700 \mathrm{~g} \mathrm{~m}^{-2}$ and $400 \mathrm{~g} \mathrm{~m}^{-2}$ in the clean and polluted cases, respectively. The clean case has four large clouds approximately $1 \mathrm{~km}^{2}$ in area, some containing drizzle reaching the surface. The polluted case has a greater number of small, shallow clouds and no drizzle. The larger concentration of aerosol in the polluted case increases the number of cloud droplets, but decreases their size [Twomey, 1977]. Since the radar reflectivity is proportional to the sixth power of droplet diameter (equation (3)), the reflectivity in the polluted case is significantly smaller than that in the clean case, providing sufficient contrast in reflectivity to investigate the effect of radar sensitivity on cloud reconstruction.

\subsection{Radar Simulator Sensitivity and Scan Modes}

[13] The success of 3D cloud field reconstruction from radar measurements is heavily dependent on the sensitivity of the radar. The minimum detectable radar reflectivity $\mathrm{dB} Z_{\text {min }}$ is determined by many factors, such as radar power, bandwidth, and dwell time, which in turn depends on the type of radar used and the scan mode deployed. The radar simulator specified in this study is based on new W-band (94 GHz) ARM scanning radars. We assume that the radar has a zero beam width with range gates of $60 \mathrm{~m}$ and is placed at the center of the domain, unless otherwise specified. We also assume that radar signal attenuation due to water vapor and other gases are perfectly corrected. Using the inverse square law, the radar sensitivity is then a function of range $r$, given as:

$$
d B Z_{\min }(r)=20 \log _{10} r+d B Z_{\min }\left(r_{0}\right)
$$

where the reference range $r_{0}$ is set as $1 \mathrm{~km}$. Depending on scan mode, ARM W-band radars have $d B Z_{\text {min }}(1 \mathrm{~km})$ ranging from -42.5 to $-32.5 \mathrm{dBZ}$. For simplicity, we use -37.5 $\mathrm{dBZ}$ at $1 \mathrm{~km}$ as the "realistic" radar sensitivity in most radar simulations.

[14] Six different radar scan modes are investigated and summarized in Table 1 and Figure 2; most are standard scan modes in the current ARM operation, except Sydney Opera HOuse (SOHO). The first scan mode, Hemispherical Sky Range Height Indictor (HSRHI), keeps a constant azimuth, changing only in elevation as it scans a 2D slice from horizon to horizon. The radar then moves azimuth by $30^{\circ}$ and repeats. The second, an original SOHO scan, changes both elevation and azimuth and is best visualized as the HSRHI scan rotated $90^{\circ}$ in elevation. The third, Plan Position Indicator (PPI), takes $2 \mathrm{D}$ slices by keeping elevation constant and completing a full $360^{\circ}$ in azimuth, before selecting a new elevation for the next slice. An advantage of the PPI scan is that it can easily be optimized for cloud height and depth. The fourth, the Sector Range Height Indicator (S-RHI) scans from a corner of the domain, making vertical slices by keeping azimuth constant for each slice with azimuth only ranging from 0 to $90^{\circ}$. The fifth, Sector PPI (S-PPI), is similar to PPI, except it also scans from a corner of the domain. Finally, the Cross-Wind RHI (CWRHI) is the same as HSRHI, except it keeps azimuth perpendicular to the wind throughout the whole scan cycle. More details can be found in the ARM instrument handbook [Widener et al., 2012].

[15] Each scan mode except CWRHI is designed to take 5 min to complete. We use a single snapshot of LES as the cloud field and assume Taylor's frozen turbulence hypothesis. In contrast, the CWRHI relies on the advection of clouds to scan the domain; therefore, a nominal wind 

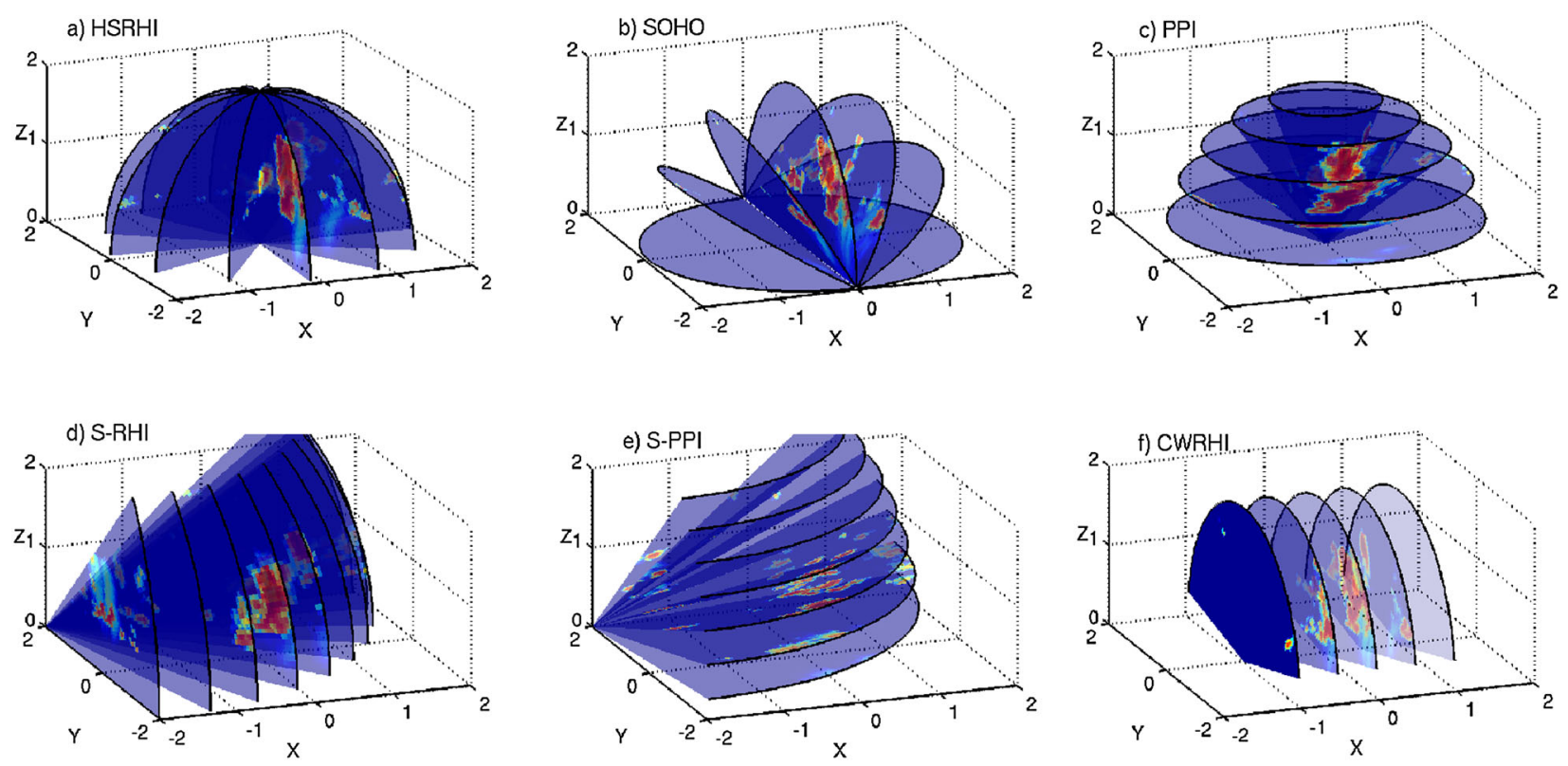

Figure 2. Visualizations of various scan modes defined in Table 1. (a) Horizon to horizon scan (HSRHI), (b) Sydney Opera HOuse (SOHO), (c) Plan position indicator (PPI), (d) Sector range height indicator (S-RHI), (e) Sector plan position indicator (S-PPI), and (f) Cross wind range height indicator (CWRHI). Colors in radar slices are for illustrative purposes only. Axes X, Y, and Z are equal in scale with an arbitrary unit.

speed of $5 \mathrm{~m} \mathrm{~s}^{-1}$ at the time of scanning requires $\sim 21 \mathrm{~min}$ to scan a domain size of $6.4 \mathrm{~km}$. As the frozen turbulence hypothesis is unlikely to be valid for such a long time window, up to 21 snapshots of LES cloud fields at $1 \mathrm{~min}$ evolution are used for the CWRHI scans.

[16] Once the scan mode is assigned, the LWC and reflectivity at each radar-scan point are given through linear interpolation from the nearest grid points of the true cloud field. If the reflectivity of the radar-scan point is smaller than the minimum detectable reflectivity, the LWC for that point is retrieved as zero. If the reflectivity of the radar-scan point exceeds the minimum detectable reflectivity, we assume that both the LWC and effective radius are perfectly retrieved and represent the truth. The impact of such an assumption is investigated in section 3.6.

\subsection{Reconstruction of 3D Cloud Fields From Radar Scans}

[17] From the LWC values collected at radar-scan points, we reconstruct the gridded 3D field using either a linear or square-root interpolation method.

[18] The linear reconstruction scheme is based on a network of tetrahedrons, generated from the irregular scanned points using a Delaunay triangulation [Delaunay, 1934]. Where a grid point value is required, a barycentric interpolation is performed from the four vertices of the tetrahedron in which the grid point lies. The result is in effect a linear interpolation from the four nearest neighbors, weighted by distance. Although this method is simple and fast, it introduces extra LWC near cloud edges due to interpolations between cloudy and cloud-free areas.

[19] The square-root reconstruction scheme was developed to mitigate the issue of extra LWC near cloud edges and to improve the overall reconstructed LWC field. Under quasi-adiabatic conditions, LWC increases approximately linearly in the vertical, but not in the horizontal across cloud edges. In situ LWC measurements for cumulus clouds often show nonlinear variations near cloud edges $[\mathrm{Lu}$ et al., 2003]. Chiu et al. [2009] also showed that ground-based zenith radiance increased exponentially near cloud edges, suggesting a nonlinear change in optical depth and in LWP. To approximate observed nonlinear variations of LWC in the horizontal, we perform a square-root transform on the LWC field before linear interpolations. After the data are gridded, we square the data back and obtain the value of LWC. This square-root approach generally sharpens cloud edges in the reconstructions, helping to offset the extra LWC introduced by interpolations between cloudy and cloud-free areas. Simultaneously, this approach alters LWC variations in the vertical, where, in some parts of the cloud, a linear relationship might be more appropriate. However, since the adiabatic cores are limited to small parts of the cloud tested here, the square-root approach is proven to provide better cloud reconstruction for our experiments, as shown in section 3.1 .

[20] In addition to LWC, cloud effective radius at each grid point needs to be specified for radiation transfer calculations. Unfortunately, we cannot grid cloud effective radius in the same manner as LWC, because such gridding does not necessarily preserve the physical relationships between these two variables shown in the truth cloud field. To confine the source of errors to the LWC field only, and to avoid additional errors from attempting effective radius interpolations between grid points, we use a power law applied to the truth and the reconstructed LWC fields to specify effective radius, ensuring both truth and reconstructed cloud fields follow the same physical relationship between LWC and cloud effective radius. This power law relationship, derived observationally [Martin et al., 1994] 
Table 2. Error Statistics in Cloud Reconstructions Using the Linear Interpolation Method for the Clean Case and Two Different Radar Sensitivities $^{\mathrm{a}}$

\begin{tabular}{|c|c|c|c|c|c|}
\hline \multirow[b]{2}{*}{ Scan Mode } & \multirow[b]{2}{*}{ Cloud Fraction } & \multicolumn{2}{|c|}{$\begin{array}{l}\text { Liquid Water } \\
\text { Path }\left(\mathrm{g} \mathrm{m}^{-2}\right)\end{array}$} & \multicolumn{2}{|c|}{$\begin{array}{c}\text { Downward Irradiance } \\
\quad\left(\mathrm{W} \mathrm{m}^{-2} \mu \mathrm{m}^{-1}\right)\end{array}$} \\
\hline & & Bias & RMSE & Bias & RMSE \\
\hline \multicolumn{6}{|c|}{ Infinite radar sensitivity; single snapshot of cloud field } \\
\hline HSRHI & 0.35 & +0.5 & 26 & -19.8 & 156.3 \\
\hline $\mathrm{SOHO}$ & 0.26 & +0.1 & 12 & -11.2 & 95.5 \\
\hline PPI & 0.27 & +0.4 & 8 & -9.5 & 82.0 \\
\hline S-RHI & 0.30 & +0.2 & 13 & -12.3 & 77.1 \\
\hline S-PPI & 0.29 & -0.1 & 12 & -10.5 & 72.8 \\
\hline \multicolumn{6}{|c|}{ Infinite radar sensitivity; multiple snapshots of cloud field } \\
\hline $\mathrm{CWRHI}^{\mathrm{b}}$ & 0.26 & -2.5 & 32 & +4.2 & 169.7 \\
\hline \multicolumn{6}{|c|}{$-37.5 \mathrm{dBZ}$ radar sensitivity at $1 \mathrm{~km} ;$ single snapshot of cloud field } \\
\hline HSRHI & 0.29 & -0.1 & 26 & -11.7 & 159.8 \\
\hline $\mathrm{SOHO}$ & 0.22 & -0.7 & 12 & -3.0 & 99.0 \\
\hline PPI & 0.22 & -0.3 & 8 & -1.4 & 88.4 \\
\hline S-RHI & 0.20 & -1.8 & 15 & +5.3 & 109.6 \\
\hline S-PPI & 0.21 & -1.7 & 14 & +3.6 & 100.4 \\
\hline \multicolumn{6}{|c|}{-37.5 dBZ radar sensitivity at $1 \mathrm{~km}$; multiple snapshots of cloud field } \\
\hline $\mathrm{CWRHI}^{\mathrm{b}}$ & 0.23 & -2.8 & 32 & +7.1 & 171.1 \\
\hline
\end{tabular}

${ }^{\text {a }}$ Cloud fields are reconstructed using the linear reconstruction method and various scan modes defined in Table 1. A positive bias represents a value larger than the truth; the true domain-averaged cloud fraction, LWP, and corresponding cloud radiative effect are $0.26,13 \mathrm{~g} \mathrm{~m}^{-2}$, and $55 \mathrm{~W} \mathrm{~m}^{-2} \mu \mathrm{m}^{-1}$, respectively. For convenience, the best performance for each column is highlighted in bold.

${ }^{b}$ Unlike other scan modes, the CWRHI uses a 21 min time window to cover the full domain and uses the full temporal evolution of the cloud field.

${ }^{c}$ Irradiances at $870 \mathrm{~nm}$ are calculated using SHDOM [Evans, 1998], with a direct beam irradiance of $950 \mathrm{~W} \mathrm{~m}^{-2} \mu \mathrm{m}^{-1}$ at a solar zenith angle of $45^{\circ}$ and an underlying black surface.

and theoretically [Liu and Hallett, 1997], is used to compute "control" cloud effective radii $r_{\mathrm{e}, \mathrm{control}}$, given as:

$$
r_{e, \text { control }}=\alpha\left(\frac{L W C}{N}\right)^{1 / 3}
$$

where $N$ is the cloud droplet number concentration and the tuning parameter $\alpha$, which represents the breadth of the size distribution, is empirically derived. To closely match the true effective radius $r_{\mathrm{e}, \text { true }}$ defined in equation (2), we set $\alpha$ to be $70 \mathrm{~g}^{-1 / 3} \mathrm{~cm}^{-1} \mathrm{~m}^{2}$, and $N$ to $50 \mathrm{~cm}^{-3}$ for the clean case and $200 \mathrm{~cm}^{-3}$ for the polluted case. As a result, for the clean case, the $r_{e, t r u e}$ field is $14 \pm 3 \mu \mathrm{m}$, the $r_{e, \text { control }}$ field is $12 \pm 3 \mu \mathrm{m}$ (mean \pm standard deviation). For the polluted case, the $r_{e, \text { true }}$ and the $r_{e, \text { control }}$ field are both $7 \pm 2 \mu \mathrm{m}$. Thus, we assume we have some a priori knowledge of $N$ and $\alpha$, which in essence means that we have a priori knowledge of $r_{e}$.

[21] To ensure replacing the LES effective radius with equation (5) does not unduly affect the radiative properties of the clouds, we calculated (see section 2.4) the difference in downwelling surface irradiance between using $r_{e, t r u e}$ and $r_{e, c o n t r o l}$ in the truth cloud fields. At an solar zenith angle of $45^{\circ}$, using the control effective radius increased irradiance by $4 \mathrm{~W} \mathrm{~m}^{-2} \mu \mathrm{m}^{-1}$ and $3 \mathrm{~W} \mathrm{~m}^{-2} \mu \mathrm{m}^{-1}$ in the clean and polluted cases, respectively. Whilst these errors are significant in relation to cloud radiative effect (around 10\%), they act only as an offset that is applied to both the truth and reconstructed effective radius fields. Even if we did use $r_{e, t r u e}$ rather than $r_{e, c o n t r o l}$ in the truth cloud fields, the error would not be large compared to other errors (shown later on in Table 6).

\subsection{Radiative Transfer Setup}

[22] Once the reconstructed cloud field is ready, the corresponding surface downwelling irradiances at $870 \mathrm{~nm}$ are calculated using the Spherical Harmonics Discrete Ordinates Method (SHDOM; Evans [1998]); we also verified results against the I3RC Community Monte Carlo radiative transfer scheme [Cahalan et al., 2005; Pincus and Evans, 2009]. The $870 \mathrm{~nm}$ wavelength, a nonabsorbing window for trace gases, water vapor, and liquid water, was chosen to emphasize the impact of errors due to scan strategy and cloud field reconstruction. The incoming solar irradiance at $870 \mathrm{~nm}$ at the top of the atmosphere (TOA) is assumed to be $950 \mathrm{~W} \mathrm{~m}^{-2} \mu \mathrm{m}^{-1}$ [Liou, 2002, p. 56]. In addition, a number of SZA ranging from $30^{\circ}$ to $60^{\circ}$ were included. The azimuthal angle of the solar irradiance is along the $\mathrm{Y}$-axis in a positive direction, i.e., $180^{\circ}$ from the top of the page. For simplicity, molecular and aerosol scattering are ignored, and a periodic boundary is assumed.

[23] For computational efficiency, the spatial resolution was reduced in radiative transfer calculations; LWC values were averaged from the fine grids to the coarse grids. The grid spacing is increased from $10 \mathrm{~m}$ to $30 \mathrm{~m}$ in the vertical and increased from $25 \mathrm{~m}$ to $75 \mathrm{~m}$ in the horizontal, based on the fact that the radar range gates are typically spaced at $60 \mathrm{~m}$. This resolution reduction is found to have negligible impact on surface irradiances in our experiments, a beneficial consequence of radiative smoothing [Marshak et al., 1995].

[24] Another important ingredient in modeling surface downwelling radiation is surface albedo. Over ocean, the surface at $870 \mathrm{~nm}$ is close to black. Over vegetated surfaces, the albedo at $870 \mathrm{~nm}$ could range between 0.25 and 0.4 [Chiu et al., 2010], based on the Collection 5 products of the Terra and Aqua Moderate Resolution Imaging Spectroradiometer (MODIS) combined data set [Schaaf et al., 2002]. We have

Table 3. Same as Table 2, but Using the Square-Root Interpolation Method for Cloud Reconstructions

\begin{tabular}{|c|c|c|c|c|c|}
\hline \multirow[b]{2}{*}{ Scan Mode } & \multirow[b]{2}{*}{ Cloud Fraction } & \multicolumn{2}{|c|}{$\begin{array}{l}\text { Liquid Water } \\
\text { Path }\left(\mathrm{g} \mathrm{m}^{-2}\right)\end{array}$} & \multicolumn{2}{|c|}{$\begin{array}{l}\text { Downwelling Irradiance } \\
\qquad\left(\mathrm{W} \mathrm{m}{ }^{-2} \mu \mathrm{m}^{-1}\right)\end{array}$} \\
\hline & & Bias & RMSE & Bias & RMSE \\
\hline \multicolumn{6}{|c|}{ Infinite radar sensitivity; single snapshot of cloud field } \\
\hline HSRHI & 0.28 & -3.7 & 27 & -4.9 & 131.5 \\
\hline $\mathrm{SOHO}$ & 0.23 & -2.9 & 14 & -0.7 & 77.8 \\
\hline PPI & 0.24 & -2.2 & 10 & -0.6 & 65.8 \\
\hline S-RHI & 0.26 & -3.1 & 16 & -1.5 & 55.9 \\
\hline S-PPI & 0.25 & -3.1 & 16 & -0.4 & 53.7 \\
\hline \multicolumn{6}{|c|}{ Infinite radar sensitivity; multiple snapshots of cloud field } \\
\hline CWRHI & 0.23 & -3.7 & 32 & +7.4 & 177.1 \\
\hline $\mathrm{PPI}^{\mathrm{a}}$ & 0.25 & -2.8 & 20 & -1.3 & 111.1 \\
\hline \multicolumn{6}{|c|}{$-37.5 \mathrm{dBZ}$ radar sensitivity at $1 \mathrm{~km}$; single snapshot of cloud field } \\
\hline HSRHI & 0.24 & -4.5 & 27 & $+\mathbf{3 . 3}$ & 141.4 \\
\hline $\mathrm{SOHO}$ & 0.19 & -3.8 & 16 & +7.3 & 93.3 \\
\hline PPI & 0.20 & $-\mathbf{3 . 0}$ & 11 & +7.3 & 86.3 \\
\hline S-RHI & 0.18 & -5.1 & 21 & +14.4 & 116.0 \\
\hline S-PPI & 0.19 & -4.9 & 19 & +13.0 & 104.7 \\
\hline \multicolumn{6}{|c|}{-37.5 dBZ radar sensitivity at $1 \mathrm{~km}$; multiple snapshots of cloud field } \\
\hline CWRHI & 0.21 & -4.1 & 32 & +11.9 & 180.7 \\
\hline $\mathrm{PPI}^{\mathrm{a}}$ & 0.20 & -3.7 & 21 & +7.1 & 124.8 \\
\hline
\end{tabular}

${ }^{\mathrm{a}}$ Unlike other scan modes, the snapshots of cloud fields in a 5 min scan period are updated every 1 min for validating the frozen turbulence assumption. 
Table 4. Same as Table 3, but for the Polluted Case ${ }^{\mathrm{a}}$

\begin{tabular}{|c|c|c|c|c|c|}
\hline \multirow[b]{2}{*}{ Scan Mode } & \multirow[b]{2}{*}{ Cloud Fraction } & \multicolumn{2}{|c|}{$\begin{array}{l}\text { Liquid Water } \\
\text { Path }\left(\mathrm{g} \mathrm{m}^{-2}\right)\end{array}$} & \multicolumn{2}{|c|}{$\begin{array}{l}\text { Downwelling Irradiance } \\
\qquad\left(\mathrm{W} \mathrm{m}^{-2} \mu \mathrm{m}^{-1}\right)\end{array}$} \\
\hline & & Bias & RMSE & Bias & RMSE \\
\hline \multicolumn{6}{|c|}{ Infinite radar sensitivity } \\
\hline HSRHI & 0.18 & -1.4 & 11 & -0.3 & 144.3 \\
\hline SOHO & 0.15 & -1.0 & 7 & +1.3 & 98.6 \\
\hline PPI & 0.14 & -0.9 & 5 & +3.4 & 91.1 \\
\hline S-RHI & 0.16 & -1.1 & 6 & +2.7 & 85.2 \\
\hline S-PPI & 0.16 & -1.0 & 6 & +2.3 & 72.1 \\
\hline \multicolumn{6}{|c|}{ Infinite radar sensitivity; multiple snapshots of cloud field } \\
\hline CWRHI & 0.18 & -0.2 & 15 & -2.0 & 188.3 \\
\hline PPI & 0.14 & -1.0 & 9 & +2.7 & 125.7 \\
\hline \multicolumn{6}{|c|}{$-37.5 \mathrm{dBZ}$ radar sensitivity at $1 \mathrm{~km}$} \\
\hline HSRHI & 0.08 & -2.4 & 13 & +19.6 & 178.2 \\
\hline $\mathrm{SOHO}$ & 0.05 & -2.3 & 10 & +20.5 & 170.9 \\
\hline PPI & 0.06 & -2.1 & 8 & +19.7 & 155.1 \\
\hline S-RHI & 0.04 & -2.8 & 12 & +26.2 & 189.7 \\
\hline S-PPI & 0.04 & -2.7 & 11 & +25.5 & 186.0 \\
\hline \multicolumn{6}{|c|}{$-37.5 \mathrm{dBZ}$ radar sensitivity at $1 \mathrm{~km} ;$ multiple snapshots of cloud field } \\
\hline CWRHI & 0.09 & -1.5 & 14 & +10.5 & 191.1 \\
\hline PPI & 0.06 & -2.2 & 11 & +19.7 & 162.8 \\
\hline
\end{tabular}

${ }^{a}$ The true domain-averaged cloud fraction, liquid water path, and corresponding cloud radiative effect are $0.18,3.75 \mathrm{~g} \mathrm{~m}^{-2}$, and $26 \mathrm{~W} \mathrm{~m}^{-2} \mu \mathrm{m}^{-1}$, respectively.

found that the relative flux error between radar scan modes varies by less than $1 \mathrm{~W} \mathrm{~m}^{-2} \mu \mathrm{m}^{-1}$ for a surface albedo range of between 0 and 0.4 . Therefore, for simplicity, we focus on results from an underlying black surface.

\subsection{Experiment Procedure}

[25] Several factors introduce errors to the resulting surface downwelling radiation during the $3 \mathrm{D}$ cloud field retrieval process:

[26] 1. Scan geometry (Experiment 1)

[27] 2. Reconstruction method (Experiment 1)

[28] 3. Radar sensitivity (Experiment 2)

[29] 4. Frozen turbulence assumption (Experiment 3)

[30] 5. Microphysical retrieval (Experiment 4)

[31] To characterize the magnitude of these errors, we conducted a series of experiments, where each subsequent experiment was independently adapted from the first experiment. The simplest, assuming infinitely sensitive radars and perfect LWC retrievals, allows us to quantify errors in surface radiation purely due to the geometry of scan strategies (e.g., errors from missing small clouds) and the LWC reconstructions themselves (e.g., errors at cloud edges). The errors introduced by radar sensitivity (e.g., the missing of both distant clouds and clouds with low LWC) are explored in Experiment 2. Adjusting the sensitivity of the radar should allow us to identify the minimal radar sensitivity required for representing surface irradiances for the cumulus clouds tested here. Experiment 3 relaxes the assumption of Taylor's frozen turbulence hypothesis, allowing the clouds to evolve when the radar scans; this allows us to quantify the general impact of the frozen turbulence assumption and to provide direct comparison of the CWRHI to other scan strategies. The many small clouds with lifetimes less than 5 min [Jiang et al., 2009] will now also contribute to the error. In Experiment 4, the effect of imperfect LWC retrievals is analysed, by introducing a retrieval method that uses a power law relationship between the truth LWC and radar reflectivity in equations (1) and (3).
[32] For evaluation purposes, the bias is often considered the most relevant statistical measure in climate science. However, since one of the main goals for scanning radar deployment is to provide detailed cloud structure for studying radiation closure and cloud life cycle, it is important that we minimize both the bias and root-mean-squared error (RMSE) in the reconstructions. Therefore, we evaluate the integrity of reconstructed cloud fields using the mean bias and RMSE of LWP across each column from the truth, and the bias in cloud fraction (CF) that is defined as the fraction of LWP greater than $1 \mathrm{~g} \mathrm{~m}^{-2}$. The threshold takes into account the increasing radiative influence of areas of cloud with LWP greater than this value. Similarly, the discrepancy in surface downwelling radiation is also quantified by the bias and RMSE of all surface pixels in the domain from the truth.

\section{Simulation Results}

\subsection{The Simplest Configuration - Perfect LWC Retrieval With Infinite Radar Sensitivity}

[33] By using perfect LWC (and hence perfect effective radius) retrievals and infinite radar sensitivity, the simplest experiment aims to investigate surface radiation discrepancy purely due to scanning geometry and cloud field reconstruction. Results for the clean case using the linear and the square-root reconstruction methods are summarized in Tables 2 and 3, respectively. The polluted case using the square-root method is summarized in Table 4.

[34] For the clean case with the linear reconstruction method (Table 2), the absolute biases in domain-averaged LWP are all within the range $0.1-0.5 \mathrm{~g} \mathrm{~m}^{-2}$ ( $<5 \%$ of the truth) except the CWRHI with $2.5 \mathrm{~g} \mathrm{~m}^{-2}(\sim 20 \%)$; specifically, the SOHO and S-PPI scans have the least bias. On the other hand, the LWP RMSE has a wide range from 8 to $32 \mathrm{~g} \mathrm{~m}^{-2}$, with the best performance from the PPI scan. Overall, all scan modes reasonably capture the statistics of the true LWP field, except the HSRHI and CWRHI scans. Since the PPI scan mode introduces a relatively low bias $(\sim 3 \%)$ and the least RMSE in LWP, it has the potential to work well for a radiation closure study and forms the basis of the following in-depth analysis.

[35] To explore the performance of using linear interpolation in the reconstructions, Figure 3 a contains a scatter plot showing reconstructed vs. truth LWC for the PPI scan. For LWC greater than $0.1 \mathrm{~g} \mathrm{~m}^{-3}$, the majority of data points are close to the 1:1 line, suggesting proper interpolations for this LWC range-cloud cores are captured correctly. However, for LWC less than $0.1 \mathrm{~g} \mathrm{~m}^{-3}$, a significant amount of LWC is overestimated in the reconstructions, leading to a poor reconstruction around cloud edges. Nonlinear variations of LWC in the truth, as discussed in section 2.3 , are likely to be the dominant cause of the overestimation.

[36] Figure 4 shows the true and reconstructed LWP and irradiance fields for the clean case, which can be used to understand the radiative impact of the reconstruction errors (the spread in Figure 3a). The horizontal structures of LWP in Figures $4 \mathrm{a}$ and $4 \mathrm{~b}$ agree well with each other; however, two distinct features warrant discussion.

[37] First, the radar misses small clouds (e.g., location A); this allows more radiation to reach the ground and introduces a positive bias in surface downwelling irradiance, as shown in Figure 4e. Whilst the direct radiation reaching the surface under the missing cloud is now much greater, the consequent 

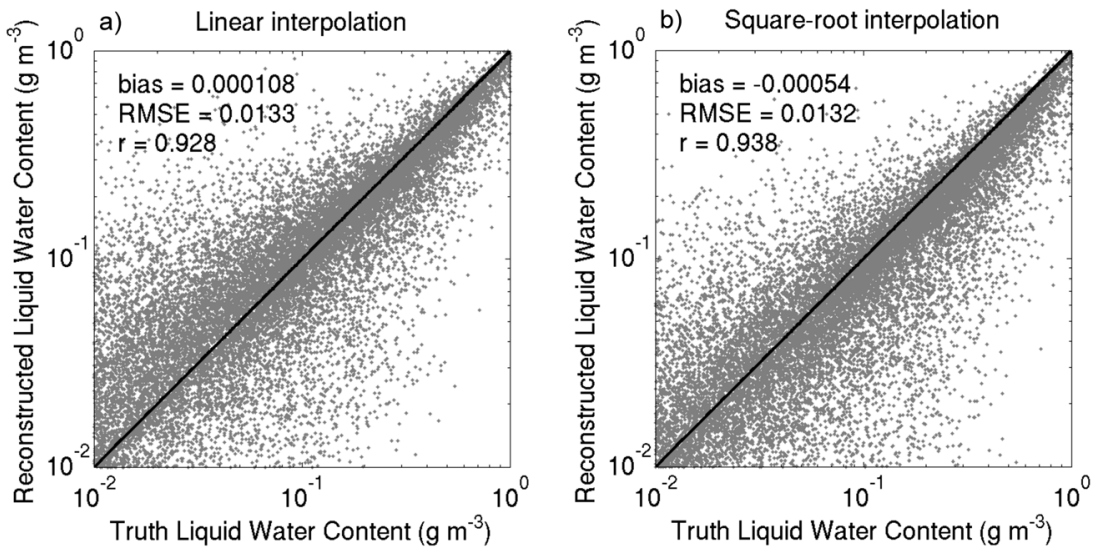

Figure 3. Scatter plots of reconstructed vs. truth liquid water content $\left(\mathrm{g} \mathrm{m}^{-3}\right)$, with infinite radar sensitivity using the PPI scan mode for the clean case. (a) uses the linear interpolation method for the reconstruction and (b) uses the square-root interpolation method. Bias (reconstructed-minus-truth), RMSE (both in $\mathrm{g} \mathrm{m}^{-3}$ ), and correlation coefficient $(r)$ are given for each scatter plot, while the black 1:1 line represents perfect reconstructions.

decrease in diffuse radiation from the cloud reduces the downwelling irradiance in adjacent areas of the domain and reduces the overall positive bias.

[38] Second, the region between cloudy and cloud-free areas of the radar scans will always contain cloud after interpolation, making the reconstructed cloud edge extend further than the truth if the radar has insufficient sampling at cloud boundaries (e.g., location B), which compounds overestimation of LWC from not representing its nonlinear variation. This erroneous extension of cloud boundaries introduces a negative bias in surface downwelling irradiance as shown by "blue-ring" areas around clouds in Figure 4e (e.g., location $\mathrm{C}$, representing the key area where the surface irradiance is influenced by the cloud in location B). For convenience, this feature is dubbed "the blue-ring effect" hereafter. In a similar way to the first feature, this negative bias is associated with a positive bias elsewhere, due to the increase in diffuse radiation from extended cloudy areas.

[39] These two features provide compensating effects on surface irradiance; the final irradiance bias depends on which feature dominates. Table 2 shows significant negative biases for the clean case except CWRHI, suggesting that the bluering effect has a major impact and introduces a negative bias in surface downwelling irradiance. The PPI scan shows a bias of $-9.5 \mathrm{~W} \mathrm{~m}^{-2} \mu \mathrm{m}^{-1}$ representing $1.5 \%$ of the TOA incident irradiance, with an RMSE of $82 \mathrm{~W} \mathrm{~m}^{-2} \mu \mathrm{m}^{-1}$ that corresponds to $12 \%$ of the incident irradiance. Whilst the irradiance bias (1.5\%) appears small, it comprises $17 \%$ of the total cloud radiative effect $\left(55 \mathrm{~W} \mathrm{~m}^{-2} \mu \mathrm{m}^{-1}\right.$ at $\left.45^{\circ} \mathrm{SZA}\right)$.

[40] For the same clean case but using the square-root reconstruction method, Table 3 shows that the bias and RMSE in surface downwelling irradiance are improved for all scan modes compared to those with the linear reconstruction method, except CWRHI. This improvement in radiation is because of better reconstruction around cloud edges for LWC smaller than $0.1 \mathrm{~g} \mathrm{~m}^{-3}$. As shown in Figure $3 \mathrm{~b}$, the majority of reconstructed LWC agree with the truth using the square-root interpolation method, which changes the sign of the bias in LWC from positive to negative and leads to a reduction in the blue-ring effect. This is further confirmed by Figures $4 \mathrm{e}$ and $4 \mathrm{f}$, showing that the irradiance in cloudfree areas also matches the truth better than that with the linear reconstruction method. Consequently, with the PPI scan, the total bias is within $1 \%$ of the incident irradiance and within $2 \%$ of the total CRE, even though the domainaveraged LWP is reduced by $17 \%$ due to sharper cloud edges. Since the bias and RMSE of LWP reveal similar information on LWC errors, our evaluations on cloud reconstructions will focus on LWP error statistics hereafter.

[41] CFs for all scan modes using both reconstruction methods agree with the truth to within $3 \%$, except the HSRHI. The HSRHI scan mode gives good vertical profiling of clouds, but this comes at a cost of leaving large areas of the domain unscanned in the horizontal, leading to blurring of the reconstructed LWP fields due to a large distance for interpolation. In broken cloud such as the shallow cumulus here, the horizontal dimensions give the dominant source of heterogeneity in the cloud field. Taking vertical slices hampers horizontal cloud edge detection, and this is why horizontal scans (such as PPI) perform better than vertical scans (HSRHI). By scanning vertically and horizontally, the SOHO scan is a compromise of the two types, and hence has errors greater than PPI, but less than HSRHI. Taking vertical slices of cloud, however, does not inherently lead to poor results if each vertical scan can be made faster and more frequently; this is highlighted by the outcome that the RMSE of irradiance for S-RHI scans is lower than other scan modes except the S-PPI scan.

[42] For the polluted case with the square-root reconstruction method (Table 4), the bias for all scan modes in downwelling irradiance ranges from -1 to $4 \mathrm{~W} \mathrm{~m}^{-2} \mu \mathrm{m}^{-1}$, if one excludes the CWRHI. The PPI scan mode has the smallest RMSE in LWP, with a corresponding downwelling irradiance bias of $3.4 \mathrm{~W} \mathrm{~m}^{-2} \mu \mathrm{m}^{-1}$ that is less than $1 \%$ of the incident irradiance but $13 \%$ of the CRE $\left(26 \mathrm{~W} \mathrm{~m}^{-2} \mu \mathrm{m}^{-1}\right)$. The reason for the increased positive bias in the polluted case compared to the clean case is twofold. First, a smaller CF in the polluted case reduces the impact of the blue-ring effect because there is less cloud upon which it can act. Second, the polluted case has a greater number of small clouds 
a) TRUTH (clean case)
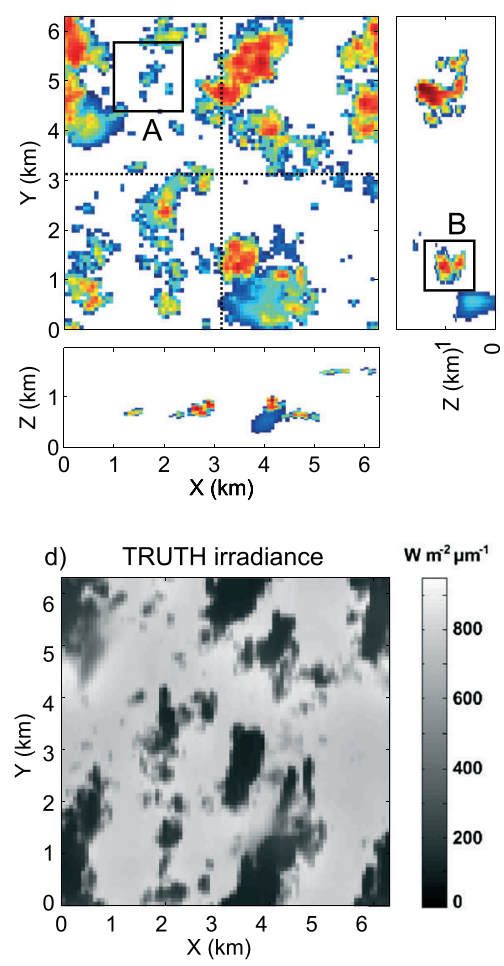

b)
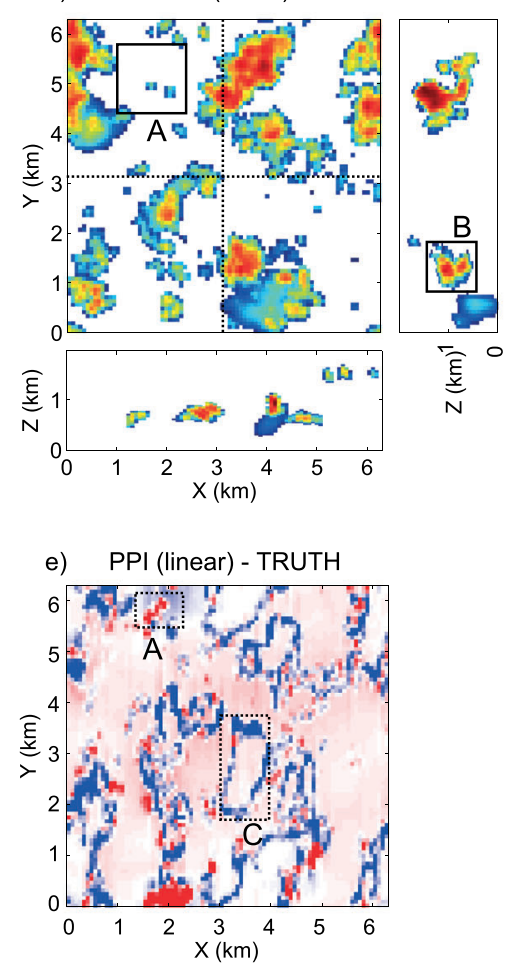
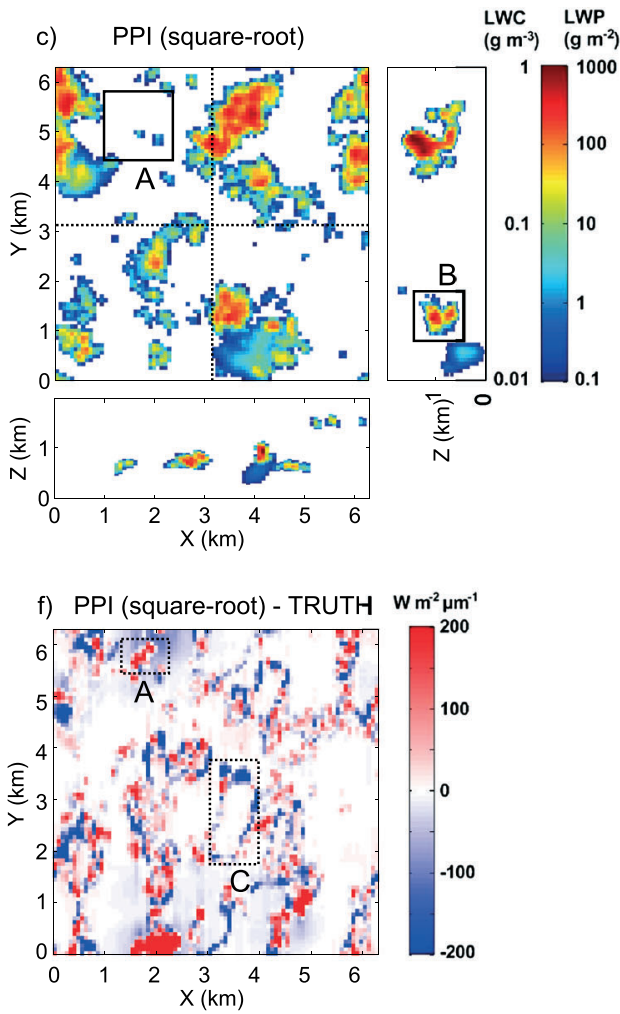

Figure 4. Evaluation of reconstructions generated from PPI scan mode with infinite radar sensitivity, using an LES-generated clean case as the "truth." (a) The main image shows the truth liquid water path (LWP $\mathrm{g} \mathrm{m}^{-2}$ ), and the right and bottom images show liquid water content $\left(\mathrm{LWC} \mathrm{g} \mathrm{m}^{-3}\right.$ ) for $\mathrm{X}=3.1 \mathrm{~km}$ and $Y=3.1 \mathrm{~km}$ respectively. ( $\mathrm{b}$ and $\mathrm{c}$ ) The same as Figure 4a, but the cloud fields were, respectively, reconstructed from the linear and square-root interpolation methods. (d) The calculated truth downwelling surface irradiance $\left(\mathrm{W} \mathrm{m}^{-2} \mu \mathrm{m}^{-1}\right)$ at $870 \mathrm{~nm}$ for solar zenith angle of $45^{\circ}$, with azimuthal angle along the $\mathrm{Y}$-axis in a positive direction. (e) The difference in the downwelling irradiance calculated from the linear interpolation reconstruction used in Figure 4b, with respect to the truth as shown in Figure 4d. (f) The same as Figure $4 \mathrm{e}$ but using the square-root interpolation method. Corresponding domain-averaged values can be found in Table 1 and 2. Labels A, B, and C are used for discussion in text.

that are more likely to be missed by the radar (as shown by location D in Figure 5b), which also adds a positive contribution to the irradiance bias.

[43] To conclude, assuming perfect LWC retrievals and infinite radar sensitivity, PPI scans show the most promise, with the smallest RMSE in LWP for both clean and polluted cases. The S-PPI also performed well, often being the scan with the lowest irradiance RMSE. In contrast, the HSRHI scan mode is not suitable for attempting radiation closure with the current radar scanning capability. The square-root reconstruction method produces the smallest biases in irradiance, so it is used exclusively for the rest of this study.

\subsection{Effect of Using a Realistic Radar Sensitivity}

[44] Introducing a realistic radar sensitivity essentially imposes a detectable threshold of LWC, which reduces the total water in the reconstructed cloud field; subsequently, this allows more radiation to reach the surface and increases the downwelling irradiance bias. The LWC threshold depends on both droplet size and sensing range - the smaller the droplet, the higher the LWC threshold; the longer the range, the higher the LWC threshold. For the clean case with a realistic radar sensitivity of $-37.5 \mathrm{dBZ}$ at $1 \mathrm{~km}$, the LWC threshold can be calculated as $\sim 0.01 \mathrm{~g} \mathrm{~m}^{-3}$ at $1 \mathrm{~km}$ and increases to $\sim 0.1 \mathrm{~g} \mathrm{~m}^{-3}$ at $5 \mathrm{~km}$. Although this threshold will not affect typical cumulus clouds that have in-cloud LWC ranging between 0.05 and $1 \mathrm{~g} \mathrm{~m}^{-3}$, the radar will begin to miss areas of LWC lower than $0.05 \mathrm{~g} \mathrm{~m}^{-3}$ at $2 \mathrm{~km}$. This could significantly impact detection of the "twilight zone" between cloudy and cloud-free areas, which still interacts with SW radiation [Koren et al., 2007].

[45] Tables 2-4 show that the downwelling irradiance bias increases in all scan modes when the realistic radar sensitivity of $-37.5 \mathrm{dBZ}$ at $1 \mathrm{~km}$ is applied. Sector-type scan modes, with the radar located at the corner of the domain, have the largest change in irradiance bias due to a large reduction in LWP. The average beam path to a cloud will be greater when the radar is at the corner of the domain compared to a strategy where the radar is at the center of the domain. The higher LWC threshold for these more distant clouds causes the reduction in LWP. For this reason, sector-type scan modes are not the best choice for radiation closure.

[46] The increase in irradiance bias introduced by the realistic radar sensitivity is more evident in the polluted case than in the clean case. For the PPI scan mode with the realistic radar sensitivity, the radar does not detect clouds that have low LWP (see difference in locations D and E between 
a) TRUTH (polluted case)
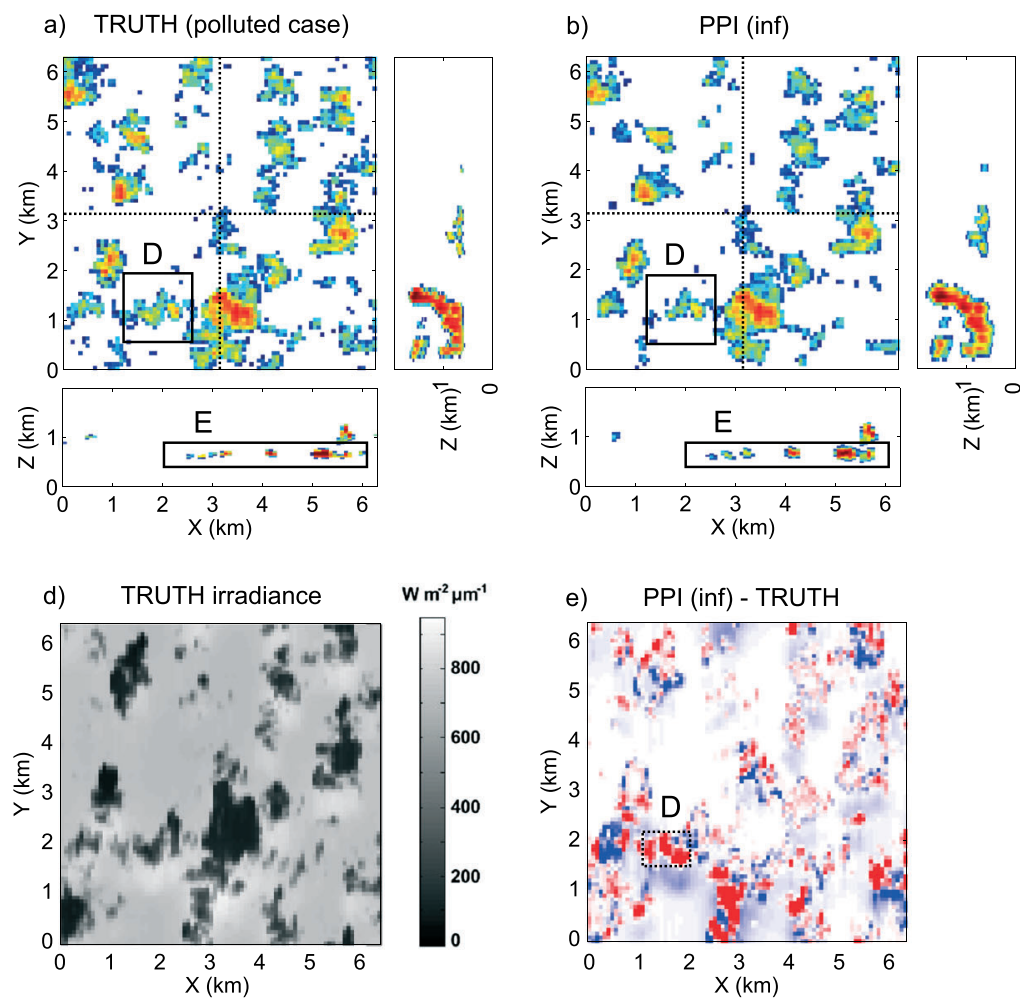

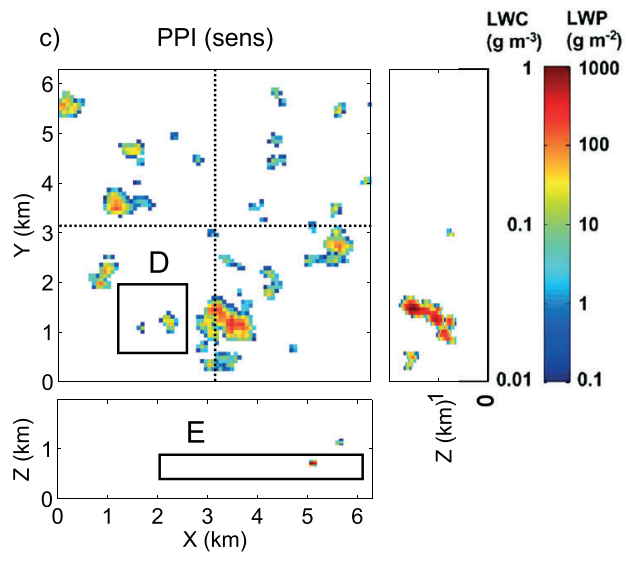

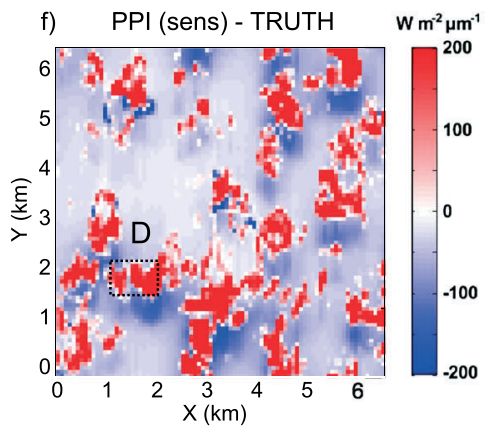

Figure 5. Comparison of reconstructed cloud fields and surface downwelling irradiance at $870 \mathrm{~nm}$ $\left(\mathrm{W} \mathrm{m} \mathrm{m}^{-2} \mu \mathrm{m}^{-1}\right)$ for the polluted case, using the PPI scan mode with infinite and realistic $\left(-37.5 \mathrm{dBZ}_{\text {min }}\right.$ at $1 \mathrm{~km}$ ) radar sensitivity. (a and d) The same as Figures $4 \mathrm{a}$ and $4 \mathrm{~d}$, but for the polluted case. (b and c) The same as Figure 5a, but the cloud fields were, respectively, reconstructed with infinite and realistic radar sensitivity. (e) The downwelling irradiance calculated from the reconstructed cloud field in Figure 5b, minus truth downwelling irradiance as shown in Figure 5d. (f) The same as Figure 5e but using the realistic radar sensitivity. Corresponding domain-averaged values can be found in Table 4 . Labels $\mathrm{D}$ and $\mathrm{E}$ are used for discussion in text.

Figures $5 \mathrm{~b}$ and $5 \mathrm{c}$ ), which decreases the domain total LWP by a further $32 \%$ of the truth. While missing clouds or reductions in reconstructed LWP increase direct downwelling irradiance (as shown by the red areas in Figure 5f), they also decrease diffuse radiation (as shown by the light blue shading). To better understand how these factors compensate each other, we examine histograms of the surface downwelling irradiance in cloudy and cloud-free areas.

[47] Similar to Schmidt et al. [2009], the frequency of occurrence of the surface downwelling irradiance for the polluted case is split into two modes: a cloud-free mode mainly dominated by direct radiation, and a cloudy mode dominated by diffuse radiation (Figure 6). The effects of the realistic radar sensitivity, through the reduction in detectable LWC (e.g., missing clouds), can be seen in both modes. First, the occurrence frequency of the distribution in the cloud-free mode increases dramatically. Second, the distributions in both modes shift to lower irradiance values and indicate a reduction of diffuse radiation in both cloud-free and cloudy areas. This reduction is because clouds missed by the radar, which have low LWP (less than $20 \mathrm{~g} \mathrm{~m}^{-2}$ ) and do not strongly reflect sunlight, are the main source of diffuse radiation reaching the surface. As a consequence, the radiation gain from the cloud-free areas outweighs the overall diffuse radiation reduction, leading to a positive bias in the domain-averaged downwelling irradiance, consistent with results in Tables 2-4.

[48] The irradiance bias remains positive for most SZA and radar sensitivities using the PPI scan mode for both clean and polluted cases (Figure 7). However, under some circumstances, the radiation gain in the cloud-free areas is balanced by the diffuse radiation reduction, which results in a negligible irradiance bias. This is seen in the clean case with a radar sensitivity of $-50 \mathrm{dBZ}$ at $1 \mathrm{~km}$, where the downwelling irradiance bias is zero compared to $-0.5 \%$ for radar with infinite sensitivity. This circumstance only occurs in the clean case, because most clouds are large and optically thick enough to be detected; the radiation gain from missing clouds is then limited and thus can be balanced by the diffuse radiation reduction.

[49] Overall, Figure 7 shows that the errors in downwelling irradiance increase with decreasing radar sensitivity. At a given SZA of $45^{\circ}$, the irradiance bias increases approximately with a rate of $0.15 \%$ of incident irradiance per $\mathrm{dB}$ in the sensitivity range between $-40 \mathrm{dBZ}$ and $-30 \mathrm{dBZ}$ at $1 \mathrm{~km}$. The minimum radar sensitivity at which the irradiance RMSE begins to increase is $-45 \mathrm{dBZ}$ at $1 \mathrm{~km}$ in the clean case and $-50 \mathrm{dBZ}$ at $1 \mathrm{~km}$ in the polluted case, emphasizing the critical level where a lack of sensitivity begins to affect the cloud field reconstructions. 

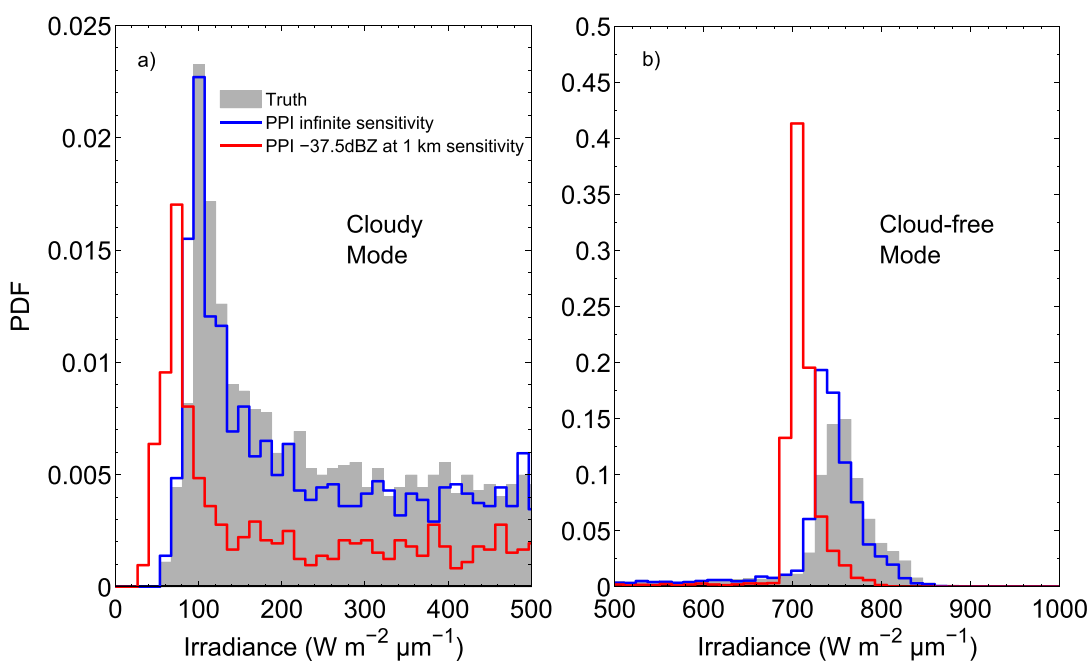

Figure 6. Occurrence frequency histograms of downwelling surface irradiance at $870 \mathrm{~nm}$ with solar zenith angle of $45^{\circ}$ and the PPI scan mode for the polluted case. For illustration purposes, the histograms are split into (a) cloudy mode with an irradiance range of $0-500 \mathrm{~W} \mathrm{~m}^{-2} \mu^{-1}$ and (b) cloud-free mode with a range of $500-1000 \mathrm{~W} \mathrm{~m}^{-2} \mu_{\mathrm{m}}^{-1}$, using different occurrence scales. Shaded areas represent histograms derived from the truth cloud field (i.e., Figure 5a). Blue lines represent histograms from the reconstructed field (i.e., Figure 5b) with infinite radar sensitivity, while red lines represent histograms from Figure 5c with radar sensitivity of $-37.5 \mathrm{dBZ}_{\min }$ at $1 \mathrm{~km}$.

\subsection{Effect of SZA}

[50] Using the PPI scan mode, Figures $7 \mathrm{a}$ and $7 \mathrm{c}$ show that the greater the SZA, the greater are the surface irradiance errors relative to the incident irradiance in both clean and polluted cases. This is because with the sun close to the horizon, the effective area for light to interact with cloud is much greater than with an overhead sun. It follows that an error in cloud structure is magnified for a greater SZA, which in turn causes larger irradiance errors. A similar effect is seen as the CRE also increases with SZA. Therefore, when considering the irradiance bias relative to CRE (Figure 7b), the impact of SZA on irradiance bias is reduced. The bias actually becomes slightly smaller for larger SZA, because the blue-ring effect has a greater radiative effect at increased SZA compared with the positive bias error contribution from missed cloud.
[51] In the polluted case, where many clouds are undetected due to the low radar reflectivity of the droplets, the positive bias in downwelling irradiance becomes very high at large SZA. A limit is reached when the radar sensitivity is so poor that it misses all clouds; hence, the bias reaches the magnitude of the truth's CRE.

\subsection{The Validity of the Frozen Turbulence Assumption}

[52] Up to now, we have used the frozen turbulence assumption for investigations of how errors in downwelling irradiance vary with scan mode, radar sensitivity, and SZA. In a 5 min scan period, however, clouds evolve. To examine the validity of the frozen turbulence assumption, we now include cloud evolution by updating cloud field snapshots every $1 \mathrm{~min}$. We
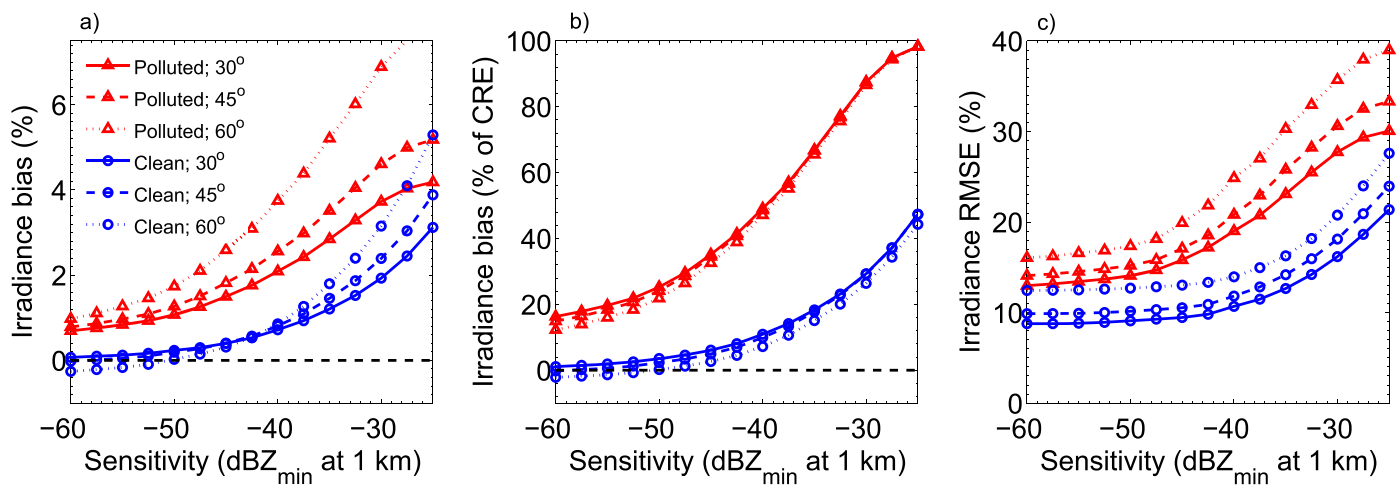

Figure 7. Errors in domain-averaged downwelling surface irradiance $\left(\mathrm{W} \mathrm{m}^{-2} \mu \mathrm{m}^{-1}\right)$ at $870 \mathrm{~nm}$ as a function of radar sensitivity at solar zenith angles of $30^{\circ}$ (solid), $45^{\circ}$ (dashed), and $60^{\circ}$ (dotted) for the clean (blue) and polluted (red) cases, using PPI scans and the square-root reconstruction method. A positive bias represents a value larger than the truth. The error is given as (a) the bias (\%); (b) the bias (\%) relative to the domain-averaged cloud radiative effect; and (c) RMSE (\%). 

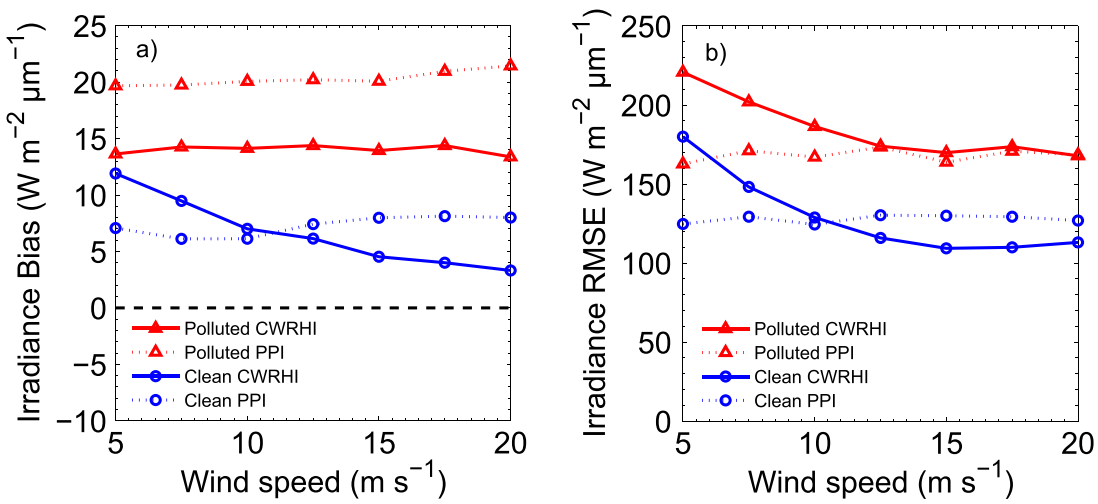

Figure 8. Effect of wind speed on (a) bias and (b) RMSE of surface downwelling irradiance $\left(\mathrm{W} \mathrm{m}^{-2} \mu \mathrm{m}^{-1}\right)$ at $870 \mathrm{~nm}$ for the clean and polluted cases, based on CWRHI and PPI scans with radar sensitivity $-37.5 \mathrm{dBZ}$ and solar zenith angle is $45^{\circ}$.

quantify additional errors by comparing results with those generated from an unvarying cloud field under the PPI scan mode.

[53] In both clean and polluted cases, the truth domainaveraged LWP varies less than 1\% between LES-generated snapshots with some growing and some decaying clouds; this leads to small changes in domain-averaged irradiance biases between cases with and without the frozen turbulence assumption when infinite radar sensitivity is applied (Tables 3 and 4). However, the irradiance RMSE increases by $45 \mathrm{~W} \mathrm{~m}^{-2} \mu \mathrm{m}^{-1}$ and $35 \mathrm{~W} \mathrm{~m}^{-2} \mu \mathrm{m}^{-1}$ when the assumption is relaxed for the clean and polluted case, respectively. The RMSE increase in the clean case of $\sim 70 \%$ is more significant than that in the polluted case $(\sim 40 \%)$. The greater increase in RMSE in the clean case might imply faster evolving clouds with short lifetimes. However, this does not agree with Jiang et al. [2009], where cloud lifetimes were found to be shorter in polluted cases in similar LES experiments. This suggests that other factors such as CF and the evolution of LWP distribution also affect the validity of the frozen turbulence assumption. Overall, the irradiance RMSE introduced by the frozen turbulence assumption is significant for cumulus clouds; so for radiation closure study, it is important to have a fast-scanning radar.

\subsection{CWRHI Scan Mode}

[54] Instead of actively scanning the domain in $3 \mathrm{D}$, the radar in the CWRHI mode scans perpendicular to the wind direction at a fixed azimuth, allowing clouds to advect across the path of the radar. Assuming a fixed scan speed, the distance between radar slices is therefore dependent on wind speed. At high wind speed, the distance between radar slices increases, which increases the interpolation distance in the reconstruction method. For example, given a scan rate of six slices per min, for a wind speed of $15 \mathrm{~m} \mathrm{~s}^{-1}$, the radar sample rate is every $150 \mathrm{~m}$, whilst at $5 \mathrm{~m} \mathrm{~s}^{-1}$, it is only $50 \mathrm{~m}$.

[55] As explained in section 2.2, the time required for the domain to be fully scanned by the radar in the CWRHI scan mode also depends on wind speed. For wind speeds between 5 and $20 \mathrm{~m} \mathrm{~s}^{-1}$, the scan periods range from 5 to $21 \mathrm{~min}$ for a $6.4 \mathrm{~km}$ domain size. Since the frozen turbulence assumption is no longer appropriate for such long scan periods, we now include cloud evolution by updating the snapshots of the LES cloud fields every minute. The cloud field at the midpoint of the scan period is chosen as the truth for all experiments tested here, which is always the same as the one used in the previous experiments for direct comparison.

[56] In the CWRHI mode, clouds are always scanned when they are at their closest point to the radar, leading to a higher detection rate of clouds with low LWC than that in the other scan modes. Overall, Tables 3 and 4 show that the CWRHI mode corresponds to the smallest error changes in both LWP and downwelling irradiance when comparing between infinite and realistic radar sensitivity.

[57] To investigate how wind speed and cloud evolution affect the performance of the PPI and CWRHI scan modes, Figure 8 shows the variations of irradiance errors with the realistic radar sensitivity for wind speed ranging between 5 and $20 \mathrm{~m} \mathrm{~s}^{-1}$. Interestingly, the irradiance errors in the PPI scan mode are not sensitive to wind speed, because the PPI changes azimuth angles and samples sufficiently in the horizontal. In contrast, the irradiance errors generally decrease with wind speed in the CWRHI scan mode. This counter-intuitive finding is a result of the fact that the domain takes a long time to be fully scanned in the case of low wind speed; clouds away from the center of the domain are likely to have changed their properties and locations, or even disappear, which consequently increases the irradiance RMSE. With increasing wind speed, the entire domain is scanned in a shorter time period, reducing the irradiance RMSE even though the spatial sampling becomes relatively poor. Not surprisingly, the final irradiance RMSE depends on the tradeoff between the spatial sampling and the time for domain coverage. When wind speed is greater than $15 \mathrm{~m} \mathrm{~s}^{-1}$, the irradiance RMSE could slightly increase as the poor sampling outweighs the fast domain coverage.

[58] A poor sampling rate increases the chance for the radar to miss cloud edges, inevitably extending cloud boundaries along the wind direction after interpolation between cloudy and cloud-free areas. This, similar to the finding in the previous experiments, introduces the blue-ring effect and further reduces the positive irradiance bias (as shown in the clean case). However, the impact of poor sampling can only become evident when there are sufficient clouds for it to act upon. In the polluted case, clouds tend to be smaller; and, with the realistic radar sensitivity, many are also not detected. As a result, any blue-ring effect is compensated by poor sampling, so we do not see a significant reduction in bias as wind speed increases. 
Table 5. Values of Parameters $a$ and $b$ Obtained for the Power Law $Z=a \cdot L W C^{b}$ and Corresponding Calculated Surface Downwelling Irradiance Errors Using the PPI Scan Mode

\begin{tabular}{|c|c|c|c|c|c|c|c|c|}
\hline \multirow[b]{2}{*}{ Variables Fitted } & \multicolumn{4}{|c|}{ Clean } & \multicolumn{4}{|c|}{ Polluted } \\
\hline & $\mathrm{a}$ & $\mathrm{b}$ & Bias & RMSE & $\mathrm{a}$ & $\mathrm{b}$ & Bias & RMSE \\
\hline Perfect LWC & - & - & -1 & 66 & - & - & +3 & 91 \\
\hline LWC vs. Z & 0.108 & 1.017 & -20 & 172 & 0.024 & 1.569 & +3 & 97 \\
\hline Z vs. LWC & 0.340 & 1.846 & -46 & 191 & 0.032 & 1.751 & -2 & 95 \\
\hline $\log _{10} L W C$ vs. dBZ & 0.110 & 1.103 & -24 & 173 & 0.039 & 1.324 & +15 & 115 \\
\hline dBZ vs. $\log _{10} L W C$ & 0.822 & 1.974 & -41 & 185 & 0.176 & 1.808 & +10 & 107 \\
\hline
\end{tabular}

Reconstruction-minus-truth bias and RMSE are calculated with direct beam irradiance of $950 \mathrm{~W} \mathrm{~m}^{-2} \mu \mathrm{m}^{-1}$, SZA of $45^{\circ}$ and infinite sensitivity radar. $a$ has units $\mathrm{mm}^{6} \mathrm{~m}^{-3}\left(\mathrm{~g} \mathrm{~m}^{-3}\right)$ and $-b$ and $b$ is unitless.

[59] Finally, the CWRH scan mode becomes superior to the PPI at wind speeds of $10-12.5 \mathrm{~m} \mathrm{~s}^{-1}$ for the clean and polluted cases, due to the smaller irradiance RMSE in Figure $8 \mathrm{~b}$. At this wind speed, the domain would be scanned in $\sim 10 \mathrm{~min}$, with all clouds in the domain scanned within $5 \mathrm{~min}$ from the midpoint of the scan period. This suggests a critical wind speed for operating the CWRHI scan mode; for cumulus clouds with advection wind speed above $\sim 10 \mathrm{~m} \mathrm{~s}^{-1}$, the CWRHI scan mode is a good choice for reconstructing cloud fields for radiation closure studies.

\subsection{Effect of Imperfect Microphysical Retrieval From Radar Reflectivity}

[60] In the previous experiments, we have assumed perfect LWC and effective radius values at radar-scanned points. In reality, LWC is commonly retrieved from radar reflectivity also using an empirically derived power law [Fox and Illingworth, 1997], where parameters $a\left(\mathrm{~mm}^{6} \mathrm{~m}^{-3}\right.$ $\left.\left(\mathrm{g} \mathrm{m}^{-3}\right)^{-\mathrm{b}}\right)$ and $b$ (unitless) are found by curve fits to in situ observations. However, when in situ observations are not available, it is difficult to evaluate how representative a particular choice of parameters is, and to quantify the uncertainty in effective radius if equation (5) is used. Empirical power law relationships are also less appropriate for precipitating clouds because the uncertainty of LWC for a given reflectivity becomes great [Hogan et al., 2005]. For example, an optically thin cloud with drizzle may have the same reflectivity as an optically thick cloud without drizzle. This is because drizzle drops tend to have a much smaller number concentration than cloud droplets, and also because reflectivity is proportional to the sixth power of drop diameter, whereas LWC is proportional to the third power. Although continual improvement has been made in many other methods for LWC retrievals [Huang et al., 2012], in particular constraining radar reflectivity with LWP measurements from microwave radiometers [Dong and Mace, 2003; Illingworth et al., 2007], uncertainty in LWC remains as large as $10-100 \%$ [Zhao et al., 2012]. Dual-wavelength radar retrievals that exploit differences in liquid water absorption at different frequencies provide the possibility to accurately retrieve LWC along the beam of the radar, but are prone to errors in radar reflectivity [Huang et al., 2009]. Another approach is to use radiance measurements to infer droplet size (e.g., McBride et al., [2011]; Chiu et al., [2012]). In precipitating cases, Lidar backscatter contains information on drizzle drop size and LWC [Westbrook et al., 2010].

[61] In this section, we investigate the suitability of a power law retrieval approach for cloud reconstructions. Suppose that a perfect profiling instrument samples droplet distributions at all grid points for the truth cloud field. We then calculate $\mathrm{Z}$ and LWC from equations (3) and (1) and conduct a fitting process to estimate parameters $a$ and $b$ in a Z-LWC power law relationship. Any drizzle below cloud base was excluded from the fit so that the fit was most appropriate for cloud droplets. We took two different fitting approaches; one uses a nonlinear least square regression in normal space (i.e., $\mathrm{Z}$ and LWC), and the other uses a linear least square regression in logarithm space (i.e., using dBZ and $\log _{10} L W C$ ). The obtained fit is also sensitive to the choice of fitting, i.e., fitting the radar reflectivity to the LWC or vice versa. The resulting power laws from these four possible ways are then applied to the radar simulator running the PPI scan mode with infinite radar sensitivity, to highlight the sole effect of imperfect LWC retrievals on surface downwelling irradiances.

[62] For drizzling clouds in the clean case, Table 5 shows that the use of the power laws significantly reduces the domain-averaged surface downwelling irradiance, with a bias ranging from -20 to $-46 \mathrm{~W} \mathrm{~m}^{-2} \mu \mathrm{m}^{-1}$. Among the four different fits, the LWC vs. Z fit has the best performance, giving a domain-averaged irradiance bias that is the lowest and closest to the bias associated with the perfect LWC retrievals. This fit corresponds to an irradiance bias of $-20 \mathrm{~W} \mathrm{~m}^{-2} \mu \mathrm{m}^{-1}$, which is $3 \%$ of the incident irradiance and $36 \%$ of the CRE. As shown in Figure 9b, the reconstructed cloud field from this fit has a much higher LWP in clouds where drizzle is present. This overestimation of LWC from radar reflectivity leads to a large negative bias error in the irradiance (e.g., see location $\mathrm{F}$ in Figure 9c). Whilst the errors in drizzle-free areas (e.g., location $G$ in Figure 9c) are not as large as those in drizzling areas (e.g., location F), the misinterpretation of drizzle as high LWC substantially increases the irradiance RMSE to $172 \mathrm{~W} \mathrm{~m}^{-2} \mu \mathrm{m}^{-1}$, much larger than the RMSE of $66 \mathrm{~W} \mathrm{~m}^{-2} \mu \mathrm{m}^{-1}$ with the perfect LWC retrieval.

[63] For nondrizzling clouds in the polluted case, the domain-averaged irradiance errors introduced from the imperfect LWC retrieval are much smaller than those in the clean case (Table 5). Similar to the clean case, the LWC vs. $\mathrm{Z}$ fit performs well; the irradiance bias from this fit is almost identical to that with the perfect $L W C$ retrieval, although the RMSE increases by $6 \mathrm{~W} \mathrm{~m}^{-2} \mu \mathrm{m}^{-1}$. The $\mathrm{Z}$ vs. LWC gives the lowest magnitude of bias and the lowest RMSE, but the bias is $5 \mathrm{~W} \mathrm{~m}^{-2} \mu \mathrm{m}^{-1}$ less than that with the perfect LWC retrieval; this is because the LWC in clouds with larger droplets is overestimated. In addition, the use of fitting in logarithm space increases downwelling irradiance, which is a result of an underestimation of LWC in clouds with small droplets (e.g., see location H in Figure 9f). 
a) TRUTH (clean case)

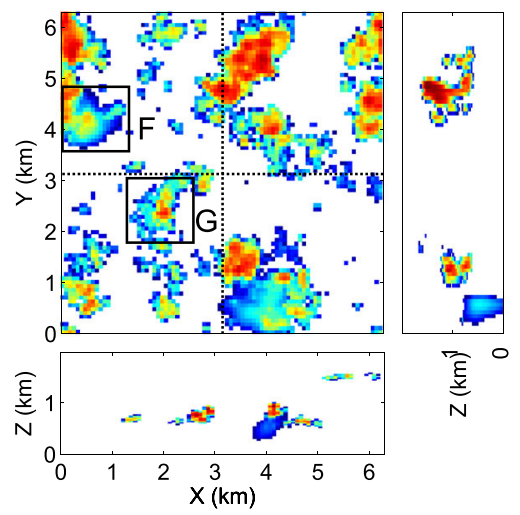

d) TRUTH (polluted case)
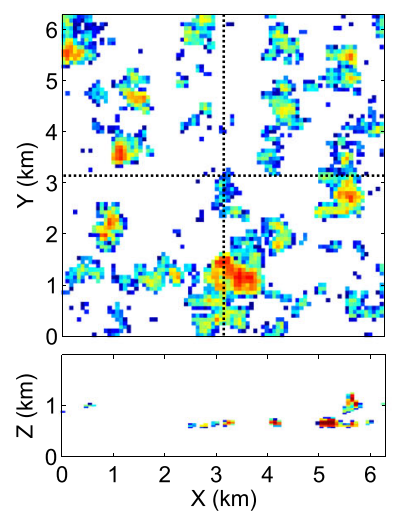

b) PPI (retrieved LWC)

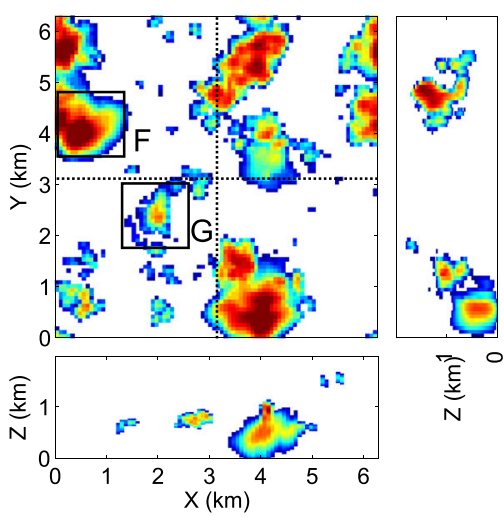

c) PPI (retrieved LWC) - TRUTH $\mathbf{W ~ m}^{-2} \mu \mathrm{m}^{-1}$

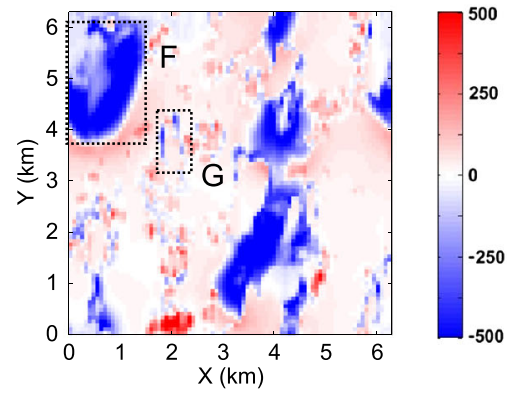

e) PPI (retrieved LWC)

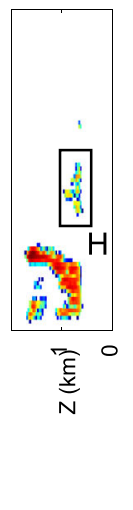

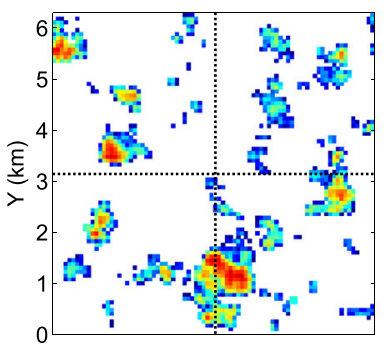

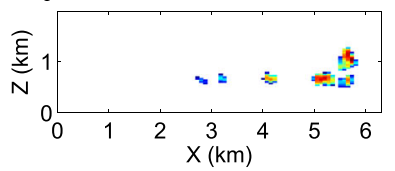

LWC LWP

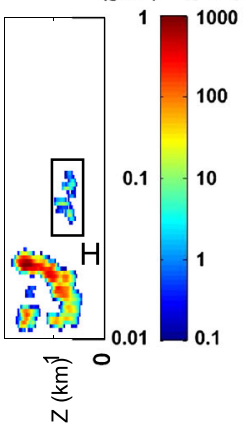

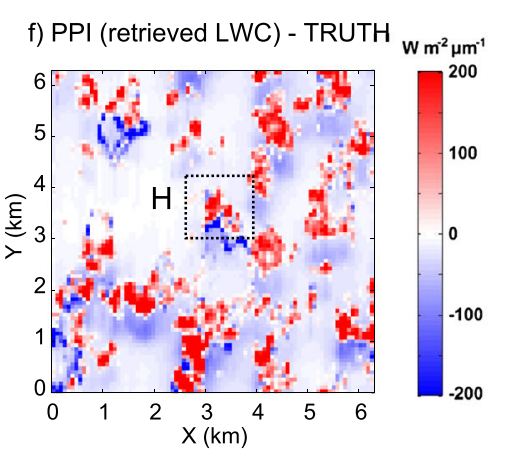

Figure 9. Effect of imperfect LWC retrievals on reconstructed cloud fields and surface downwelling irradiance bias at $870 \mathrm{~nm}$ at solar zenith angle of $45^{\circ}$ with infinite sensitivity and PPI scan mode, for the clean (top row) and polluted (bottom row) cases. (a) The same as Figure 4a, showing the truth LWP $\left(\mathrm{g} \mathrm{m}^{-2}\right)$ and vertical slices of LWC $\left(\mathrm{g} \mathrm{m}^{-3}\right)$ for $X=3.1 \mathrm{~km}$ and $Y=3.1 \mathrm{~km}$. (b) The same as Figure 9a, but for the reconstructed cloud field using LWC retrievals from $Z=0.108 L W C^{1.017}$. (c) The corresponding irradiance difference between reconstruction and the truth. (d-f) The same as Figures 9a, 9b, and 9c, respectively, but using $Z=0.024 L W C^{1.569}$ for the polluted case. Note Figures $9 \mathrm{c}$ and $9 \mathrm{f}$ have a different scale. Labels $\mathrm{F}, \mathrm{G}$, and $\mathrm{H}$ are used for discussion in text.

[64] To conclude, in nondrizzling clouds, given a good knowledge of the droplet size distribution of the clouds, a Z-LWC power law can be used to provide LWC retrievals that only introduce a small domain-averaged irradiance error compared with that from perfect LWC retrievals. In drizzling clouds, the large spread of LWC values for a given dBZ significantly hinders an accurate retrieval using radar reflectivity alone. In both cases, the nonlinear fitting of $Z$ to LWC yields the smallest additional irradiance errors.

\subsection{Comparison of Errors and Discussion}

[65] To compare the relative contribution of errors introduced by individual sources using the PPI scan mode, Table 6 summarizes bias and RMSE in surface downwelling irradiance at $870 \mathrm{~nm}$ from all experiments. The relative contribution is quantified by comparing each case with perfect LWC retrievals and infinite radar sensitivity.

[66] In the clean case, the imperfect LWC retrieved from empirical Z-LWC relationships is the primary source of irradiance bias and RMSE, due to the presence of drizzle. As explained in section 3.6, the dominance of the sixth moment in the drop size distribution of drizzle leads to significant overestimation of LWC, which reduces surface downwelling irradiance and results in a large negative bias. The large irradiance errors suggest that a more sophisticated retrieval method is needed to better characterize both cloud droplets and drizzle (e.g., Matrosov [2009]) for a radiation closure study.

[67] Also, in the clean case, the second greatest source of bias is radar sensitivity. Unlike the effect of imperfect LWC retrievals, applying realistic radar sensitivity inevitably misses clouds with low LWC, which increases surface downwelling irradiance and results in a positive bias. Overall, the increase in irradiance bias and RMSE is approximately three times less than that introduced by the imperfect LWC retrievals.

[68] In the polluted case, both the imperfect LWC retrieval and frozen turbulence assumption introduce negligible irradiance bias with limited increase in RMSE. Due to the absence of drizzle, realistic radar sensitivity becomes the primary source of irradiance errors. As explained in sections 2.1 and 3.2, clouds in the polluted case have lower LWC and smaller droplet sizes, which lowers radar reflectivity, and are easily missed. This leads to a large positive bias in surface downwelling 
Table 6. A Summary of Errors in Surface Downwelling Irradiance $\left(\mathrm{W} \mathrm{m}^{-2} \mu \mathrm{m}^{-1}\right)$ Using the PPI Scan Mode ${ }^{\mathrm{a}}$

\begin{tabular}{|c|c|c|c|c|}
\hline \multirow[b]{2}{*}{ Source of Error } & \multicolumn{2}{|c|}{ Clean } & \multicolumn{2}{|c|}{ Polluted } \\
\hline & Bias & RMSE & Bias & RMSE \\
\hline Scan geometry / Reconstruction ${ }^{\mathrm{b}}$ & $-0.6(-)$ & $65.8(-)$ & $+3.4(-)$ & $91.1(-)$ \\
\hline Realistic radar sensitivity $^{\mathrm{c}}$ & $+7.3(+7.9)$ & $86.3(20.5)$ & $+19.7(+16.3)$ & $155.1(64.0)$ \\
\hline Frozen turbulence assumption ${ }^{\mathrm{d}}$ & $-1.3(-0.7)$ & $111.1(45.3)$ & $+2.7(-0.7)$ & $125.7(34.6)$ \\
\hline Imperfect $\mathrm{LWC}$ retrieval $^{\mathrm{e}}$ & $-20(-19)$ & $172(106)$ & $+3(0)$ & $97(6)$ \\
\hline
\end{tabular}

${ }^{\text {a }}$ Direct beam irradiance is $950 \mathrm{~W} \mathrm{~m}^{-2} \mu \mathrm{m}^{-1}$ at $870 \mathrm{~nm}$ and solar zenith angle is $45^{\circ}$. Values in parentheses are the change in error relative to those derived with infinite radar sensitivity and perfect LWC retrieval (i.e., difference from the first row).

${ }^{\mathrm{b}}$ Errors are duplicated from Tables 3 and 4 , with infinite radar sensitivity and single cloud field snapshot.

${ }^{\mathrm{c}} \mathrm{Same}$ as ${ }^{\mathrm{b}}$, but with radar sensitivity of $-37.5 \mathrm{dBZ}$ at $1 \mathrm{~km}$.

${ }^{\mathrm{d}}$ Same as ${ }^{\mathrm{b}}$, but with multiple cloud field snapshots.

${ }^{\mathrm{e}}$ Errors are duplicated from Table 5, with the fit of LWC vs. Z.

irradiance. To reduce the overall irradiance errors introduced by realistic radar sensitivity, synergy with other instruments is needed. For example, measurements from a lidar that scans along the same direction as radar would help quantify optically thin clouds and resolve cloud boundaries. In addition, the clearsky lidar backscatter could also provide at least some insight in to aerosol particles surrounding the clouds.

[69] The aforementioned results have focused on domainaveraged irradiance errors. In reality, ground-based irradiance measurements are often collected from a single location near the radar so radiation closure studies need to be performed at a point, rather than the entire domain. In that case, perfect cloud reconstructions in the corners of the domain (i.e., far away from the radar) would be less important, particularly for situations with small SZA and low clouds that have smaller effective areas of radiation compared to others. Instead, accurate specification of LWC and effective radius along the path of the solar direct beam to the radar becomes crucial for radiation closure. Therefore, additional radar scans around the solar disk would help better resolve cloud boundaries near the path, increasing confidence in the estimate of direct beam radiation reaching the surface, and meanwhile confining errors to radiation scattered from other directions.

\section{Conclusions and Summary}

[70] For the purpose of surface radiation study, six scan strategies for scanning cloud radar coupled with linear or square-root interpolation schemes have been compared in terms of their ability to reconstruct 3D LWC cloud fields of shallow cumulus in clean and polluted aerosol conditions. The square-root construction scheme was found to be superior to the linear interpolation and was used for the majority of the study. Radar sensitivity was seen to play an important role in a scan strategy's success, particularly in polluted cases, where cloud droplets tend to be smaller and less easily detectable. Cloud edges and low LWP clouds were found to produce the most error to the radiation fields, as expected considering the nonlinear relationship between optical depth and transmittance. Domain-averaged surface downwelling irradiance bias at $870 \mathrm{~nm}$ was within $15 \mathrm{~W} \mathrm{~m}^{-2} \mu \mathrm{m}^{-1}(\sim 27 \%$ of the CRE) in the clean case for all scan modes and $10-26 \mathrm{~W} \mathrm{~m}^{-2} \mu \mathrm{m}^{-1}$ ( $\sim 40-100 \%$ of the CRE) in the polluted case, given a radar with realistic sensitivity over a $5 \mathrm{~min}$ time window at SZA of $45^{\circ}$. Biases were larger for greater SZA in both the absolute and relative sense. For both cases, the RMSE of downwelling irradiance was often high (10-30\% of incident irradiance), as small errors in cloud position or cloud edges made point comparisons between reconstructed fields and truth difficult. This would be higher for real observations as the wind speed across the domain would not be perfectly retrieved.

[71] To choose a "best" strategy, the simplicity of the CWRHI coupled with errors similar to the other scan strategies makes it a strong candidate for radiation closure study. It also is the most effective at detecting low reflectivity clouds and thus would be the best scan strategy for minimizing overall bias in LWC and irradiance. The frequent return to zenith gives good vertical coverage, allowing detection of high cloud. The major drawback is poor performance under low wind speed conditions, leading to high RMSE of the SW irradiance. For slow wind speed or large SZA, the PPI scan outperforms the other scan strategies and can easily be optimized with information on cloud base and height. The SOHO scan generally gave inferior results compared to the PPI scan, but its geometry would make it a good candidate for detecting high clouds. The HSRHI scan must be adapted to minimize "silent" patches that can occur where parts of the domain are left unscanned. Even after compensating for this, the horizontal coverage is not as good as SOHO or PPI. Sector-PPI and Sector-RHI scans were often found to have insufficient sensitivity to low LWP cloud, introducing large RMSE and bias errors in the irradiance.

[72] The experiments performed here provide valuable insight for decision making in deploying scanning cloud radar and highlight different scanning strategies' strengths and weaknesses for reconstructing cloud fields for SW radiation closure.

[73] Acknowledgments. This research was supported by the Office of Science (BER), U.S. Department of Energy (DOE) under grant DESC0007233. The authors would like to thank Tamás Várnai for his help verifying SHDOM against the I3RC Monte Carlo model, Hongli Jiang for her efforts in producing the LES cloud fields, and Allison McComiskey for her help extracting the LES data. GF acknowledges DOE's Office of Science (BER) and NOAA's Climate Goal for support.

\section{References}

Ackerman, T. P., and G. M. Stokes (2003), The Atmospheric Radiation Measurement Program, Phys. Today, 56, 38-44, doi:10.1063/1.1554135. Benner, T. C., and K. F. Evans (2001), Three-dimensional solar radiative transfer in small tropical cumulus fields derived from high-resolution imagery, J. Geophys. Res., 106, 14,975-14,984, doi:10.1029/2001JD900158.

Cahalan, R. F., et al. (2005), The International Intercomparison of 3D Radiation Codes (I3RC): Bringing together the most advanced radiative 
transfer tools for cloudy atmospheres, Bull. Am. Meteorol. Soc., 86, 1275-1293, doi:10.1175/BAMS-86-9-1275.

Chiu, J. C., A. Marshak, Y. Knyazikhin, P. Pilewski, and W. J. Wiscombe (2009), Physical interpretation of the spectral radiative signature in the transition zone between cloud-free and cloudy regions, Atmos. Chem. Phys., 9, 1419-1430, doi:10.5194/acp-9-1419-2009.

Chiu, J. C., C.-H. Huang, A. Marshak, I. Slutsker, D. M. Giles, B. N. Holben, Y. Knyazikhin, and W. J. Wiscombe (2010), Cloud optical depth retrievals from the Aerosol Robotic Network (AERONET) cloud mode observations, J. Geophys. Res., 115, D14202, doi:10.1029/2009JD013121.

Chiu, J. C., A. Marshak, C.-H. Huang, T. Várnai, R. J. Hogan, D. M. Giles, B. N. Holben, E. J. O’Connor, Y. Knyazikhin, and W. J. Wiscombe (2012), Cloud droplet size and liquid water path retrievals from zenith radiance measurements: examples from the Atmospheric Radiation Measurement Program and the Aerosol Robotic Network, Atmos. Chem. Phys., 12, 10,313-10,329, doi:10.5194/acp-12-10313-2012.

Delaunay, B. (1934), Sur la sphere vide. A la memoire de Georges Voronoi. Izv. Akad. Nauk SSSR, Otdelenie Matematischeskih I Estestvennyh Nauk, 7:793-800

Di Giuseppe, F., and A. M. Tompkins (2003), Effect of spatial organisation on solar radiative transfer in three-dimensional idealized stratocumulus cloud fields, J. Atmos. Sci., 60, 1774-1794, doi:10.1175/1520-0469 (2003) $060<1774$ :EOSOOS $>2.0$. CO; 2 .

Dong, X., and G. Mace (2003), Profiles of low-level stratus cloud microphysics deduced from ground-based measurements, J. Atmos. Oceanic Technol., 20, 42-53, doi:10.1175/1520-0426(2003)020<0042:POLLSC > 2.0.CO;2.

Evans, K. F. (1998), The spherical harmonics discrete ordinate method for three atmospheric radiative transfer, J. Atmos. Sci., 55, 429-446, doi:10.1175/1520-0469(1998)055<0429:TSHDOM>2.0.CO;2

Evans, K. F., and W. J. Wiscombe (2005), An algorithm for generating stochastic cloud fields from radar profile statistics, Atmos. Res., 72, 263-289, doi:10.1016/j.atmosres.2004.03.016.

Fox, N. I., and A. J. Illingworth (1997), The retrieval of stratocumulus properties by ground-based radar, J. Appl. Meteorol., 36, 485-492, doi:10.1175/1520-0450(1997)036<0485:TROSCP $>2.0$. CO;2.

Hinkelman, L. M., K. F. Evans, E. E. Clothiaux, T. P. Ackerman, and P. W. Stackhouse (2007), The Effect of Cumulus Cloud Field Anisotropy on Domain-Averaged Solar Fluxesand Atmospheric Heating Rates, J. Atmos. Sci., 64, 3499-3520, doi:10.1175/JAS4032.1.

Hogan, R. J., and S. F. Kew (2005), A 3D stochastic cloud model for investigating the radiative properties of inhomogeneous cirrus clouds, $Q$. J.R. Meteorolog. Soc., 131, 2585-2608, doi:10.1256/qj.04.144.

Hogan, R. J., N. Gaussiat, and A. J. Illingworth (2005), Stratocumulus Liquid Water Content from Dual-Wavelength Radar, J. Atmos. Oceanic Technol., 22, 1207-1218, doi:10.1175/JTECH1768.1.

Huang, D., K. Johnson, Y. Liu, and W. Wiscombe (2009), Retrieval of cloud liquid water vertical distributions using collocated Ka-band and W-band cloud radars, Geophys. Res. Lett., 36, L24807, doi:10.1029/ 2009GL041364.

Huang, D., C. Zhao, M. Dunn, X. Dong, G. G. Mace, M. P. Jensen, S. Xie, and Y. Liu (2012), An intercomparison of radar-based liquid cloud microphysics retrievals and implications for model evaluation studies, Atmos. Meas. Tech., 5, 1409-1424, doi:10.5194/amt-5-1409-2012.

Illingworth, A. J., et al. (2007), Cloudnet - Continuous evaluation of cloud profiles in seven operational models using ground-based observations, Bull. Am. Meteorol. Soc., 88, 883-898, doi:10.1175/BAMS-88-6-883.

Jiang, H., G. Feingold, and I. Koren (2009), Effect of aerosol on trade cumulus cloud morphology, J. Geophys. Res., 114, D11209, doi:10.1029/ 2009JD011750.

Koren, I., L. A. Remer, Y. J. Kaufman, Y. Rudich, and J. V. Martins (2007), On the twilight zone between clouds and aerosols, Geophys. Res. Lett., 34, L08805, doi:10.1029/2007GL029253.

Koren, I., L. Oreopoulos, G. Feingold, L. A. Remer, and O. Altaratz (2008), How small is a small cloud?, Atmos. Chem. Phys., 8, 3855-3864, doi:10.5194/acp-8-3855-2008.

Liou, K. N. (2002), An introduction to Atmospheric Radiation, 2nd ed., Academic, San Diego, Calif.

Liu, Y., and J. Hallett (1997), The "1/3" power-law between effective radius and liquid-water content, Q. J. R. Meteorolog. Soc., 123, 1789-1795, doi:10.1256/smsqj.54219.
Lu, M.-L., J. Wang, A. Freedman, H. H. Jonsson, R. C. Flagan, R. A. McClatchey, and J. H. Seinfeld (2003), Analysis of humidity halos around trade wind cumulus clouds, J. Atmos. Sci., 60, 1041-1059, doi:10.1175/1520-0469(2003)60<1041:AOHHAT > 2.0.CO;2.

Marshak, A., A. Davis, W. Wiscombe, and R. Cahalan (1995), Radiative smoothing in fractal clouds, J. Geophys. Res., 100, 26,247-26,261, doi:10.1029/95JD02895.

Martin, G. M., D. W. Johnson, and A. Spice (1994), The measurement and parameterization of effective radius of droplets in the warm stratocumulus clouds, J. Atmos. Sci., 51, 1,823-1,842, doi:10.1175/1520-0469(1994) 051<1823:TMAPOE $>2.0 . \mathrm{CO} ; 2$.

Matrosov, S. Y. (2009), Simultaneous estimates of cloud and rainfall parameters in the atmospheric vertical column above the Atmospheric Radiation Measurements Program Southern Great Plains site, J. Geophys. Res., 114, D22201, doi:10.1029/2009JD01200410.1029/2005JD006341.

McBride, P. J., K. S. Schmidt, P. Pilewskie, A. S. Kittelman, and D. E. Wolfe (2011), A spectral method for retrieving cloud optical thickness and effective radius from surface-based transmittance measurements, Atmos. Chem. Phys., 11, 7235-7252, doi:10.5194/acp-11-7235-2011.

Pincus, R., and K. F. Evans (2009), Computational cost and accuracy in calculating three-dimensional radiative transfer: Results for new implementations of Monte Carlo and SHDOM, J. Atmos. Sci., 66, 3131-3146, doi:10.1175/ 2009JAS3137.1.

Pincus, R., C. Hannay, and K. F. Evans (2005), The accuracy of determining three-dimensional radiative transfer effects in cumulus clouds using ground-based profiling instruments, J. Atmos. Sci., 62, 2284-2293, doi:10.1175/JAS3464.1.

Prigarin, S., and A. Marshak (2009), A simple stochastic model for generating broken cloud optical depth and cloud top height fields, J. Atmos. Sci., 66, 92-104.

Randall, D. A., et al. (2007), Climate Change 2007: the Physical Science Basis. Contribution of Working Group I to the Fourth Assessment Report of the Intergovernmental Panel on Climate Change, Cambridge University Press, chap 8: "Climate models and their evaluation".

Rossow, W. B., and R. A. Schiffer (1999), Advances in understanding clouds from the International Satellite Cloud Climatology Project, Bull. Am. Meteorol. Soc., 80, 2261-2287.

Schaaf, C. B. et al. (2002), First operational BRDF, albedo nadir reflectance products from MODIS, Remote Sens. Environ., 83(1-2), 135-148.

Schmidt, K. S., V. Venema, F. Di Giuseppe, R. Scheirer, M. Wendisch, and P. Pilewskie (2007), Reproducing cloud microphysical and irradiance measurements using three 3D cloud generators, Q. J. R. Meteorolog. Soc., 133, 765-780, doi:10.1002/qj.53.

Schmidt, K. S., G. Feingold, P. Pilewskie, H. Jiang, O. Coddington, and M. Wendisch (2009), Irradiance in polluted cumulus fields: Measured and modelled cloud-aerosol effects, Geophys. Res. Lett., 36, L07804, doi:10.1029/2008GL036848.

Shonk, J. K. P., R. J. Hogan, and J. Manner (2012), Impact of improved representation of horizontal and vertical cloud structure in a climate model, Clim Dyn, 38, 2365-2376, doi:10.1007/s00382-011-1174-2.

Stephens, G. L. (2005), Cloud feedbacks in the climate system: a critical review, J Clim, 18, 237-273, doi:10.1175/JCLI-3243.1.

Twomey, S. (1977), The influence of pollution on the short wave albedo of clouds, J. Atmos. Sci., 34, 1149-1152.

VanZanten, M. C. et al. (2011), Controls on precipitation and cloudiness in simulations of trade-wind cumulus as observed during RICO, J. Adv. Model. Earth Syst., 3, M06001, doi:10.1029/2011MS000056.

Venema, V., S. Meyer, S. G. Garcia, A. Kniffka, C. Simmer, S. Crewell, U. Löhnert, T. Trautmann, and A. Macke (2006), Surrogate cloud fields generated with the iterative amplitude adapted Fourier transform algorithm, Tellus Ser. A, 58, 104-120, doi:10.1111/j.1600-0870.2006.00160.x.

Westbrook, C. D., R. J. Hogan, E. J. O’Connor, and A. J. Illingworth (2010), Estimating drizzle drop size and precipitation rate using two-colour lidar measurements, Atmos. Meas. Tech., 3(3), 671-681, doi:10.5194/amt-3-671-2010.

Widener, K., N. Bharadwaj, and K. Johnson (2012), Scanning ARM Cloud Radar (X/Ka/W-SACR) Handbook, Technical Report for United States Department of Energy Office of Science Atmospheric Radiation Measurement Program, doi:10.2172/1043296.

Zhao, C., et al. (2012), Toward understanding of differences in current cloud retrievals of ARM ground-based measurements, J. Geophys. Res., 117, D10206, doi:10.1029/2011JD016792. 